\title{
El currículo flexible en la educación artística bogotana: ¿una experiencia de equidad o inequidad?*
}

\author{
The Flexible Curriculum of the Artistic Education in Bogotá: Either a Fairness or Unfairness Experience?
}

\author{
Jorge Alberto Acuña Castillo ${ }^{\text {a }}$ \\ Pontificia Universidad Javeriana, Colombia \\ ja.acunac@javeriana.edu.co \\ ORCID: http://orcid.org/0000-0002-9220-4267
}

DOI: https://doi.org/10.11144/Javeriana.papo24-1.cfea Redalyc: http://www.redalyc.org/articulo.oa $: \mathrm{id}=77760192008$

Fecha de recepción: 07 Mayo 2018 Fecha de aprobación: 04 Octubre 2018 Fecha de publicación: 24 Junio 2019

\section{Resumen:}

Este artículo sintetiza una investigación realizada para evaluar la efectividad de la política de flexibilización curricular que se implementó para mejorar la inclusión y la calidad de la enseñanza en los colegios de Colombia, centrándose en determinar si esta estrategia ha sido eficaz para garantizar el derecho a la educación artística en condiciones de equidad. Se analizaron y compararon las trayectorias de las experiencias significativas de educación artística en básica y media que fueron reconocidas durante la implementación del Plan Nacional de Educación Artística, 2007-2010, utilizando criterios para el logro de equidad que surgieron de estudiar las orientaciones pedagógicas para educación artística en Básica y Media del Ministerio de Educación y el esquema de las 4 Aes de Katarina Tomasevski, bajo dos (2) enfoques teóricos: La Justicia como Equidad de John Rawls y El Enfoque de las Capacidades de Amartya Sen y Martha Nussbaum. Se encontró que esta estrategia no ha sido del todo eficaz para garantizar este derecho en condiciones de equidad, tanto a nivel interno como externo de las instituciones educativas, por tres factores: 1) el desconocimiento que existe sobre este derecho, 2) el poco tiempo escolar asignado para la enseñanza artística, y 3) una desregulada política sobre flexibilización curricular.

Palabras clave: derecho a la educación artística, descentralización educativa, flexibilidad curricular, equidad.

\begin{abstract}
:
This article summarizes a research conducted to evaluate the effectiveness of the policy to make flexible the curriculums, which was implemented in order to improve the inclusion and quality of the teaching in the Colombian schools. The work focuses on determining whether this strategy has been effective in ensuring the right to artistic education under fair conditions. The trajectories of the significant experiences in the artistic education at the basic and intermediate school grades and recognized during the implementation of the National Plan of Artistic Education 2007-2010 were analyzed and compared. It was carried out by using criteria for fair achievement stemming from the study of the pedagogical orientations in the artistic education at the basic and intermediate school grades, as provided by the National Ministry of Education, and by using the 4-A scheme by Katarina Tomasevski, under two (2) theoretical approaches: Justice as Fairness by John Rawls, and the Capability Approach by Amartya Sen and Martha Nussbaum. It was found that this strategy has not been effective enough to ensure the said right under fair conditions, both inside and outside the educative institutions, due to three factors: 1) Lack of awareness on this right; 2) the short time allocated in the school to the artistic teaching; and 3) non-regulated policy on how to make flexible the curriculums.
\end{abstract}

Keywords: right to artistic education, educative decentralization, curricular flexibility, equity.

\section{Introducción}

En 1998, la primera relatora especial de las Naciones Unidas sobre el derecho a la educación, de la Comisión de las Naciones Unidas sobre Derechos Humanos, Katarina Tomasevski (1953-2006), explicó que la promesa de la declaración universal de los derechos humanos de 1948 tuvo como objeto primordial y fundamental, defender la humanidad de las personas frente a los abusos de poder gubernamentales, que esclavizan a los

Notas de autor:

a Autor de correspondencia. Correo electrónico: ja.acunac@javeriana.edu.co 
pueblos, al quitarles la oportunidad de aprender conocimientos que garantizan su libertad. Por esta razón, surgió el derecho a la educación en 1966, para acentuar aún más la responsabilidad de los Estados en su deber de brindar una educación de calidad y en correspondencia con los demás derechos humanos (Tomasevski, 2004).

Bajo esta perspectiva, a comienzos del nuevo siglo, la Organización de las Naciones Unidas para la Educación, la Ciencia y la Cultura (Unesco) señaló la marginalidad que sufren las artes en los modelos educativos, que la educación artística "es un derecho universal para todos los educandos, comprendidas las personas que suelen quedar excluidas de la educación, como por ejemplo los inmigrantes, las minorías culturales y las personas discapacitadas" (Unesco, 2006, p. 5). Se explicó que esta declaración está respaldada en la Declaración Universal de los Derechos Humanos y en la convención sobre Derechos del Niño, las cuales tienen como propósito garantizar a niños y adultos su derecho a recibir una educación que les permita el pleno y armonioso desarrollo de sus capacidades, al mismo tiempo que participan en la vida artística y cultural de sus naciones (Unesco, 2006).

También declaró que la cultura y las artes son componentes básicos de una educación integral, y que por esta razón la educación artística no solo debe ser asumida como un componente en los programas educativos que articulan los campos del conocimiento y de la experiencia humana, sino también como un derecho universal que garantiza el cumplimiento pleno de los demás derechos fundamentales, especialmente a la educación y a la cultura (Unesco, 2006). Por ello, la enseñanza de las artes en la educación básica y media es de suma importancia, ya que al facilitar el aprendizaje y la participación de las personas en experiencias, procesos y desarrollos creativos, al estimular sus iniciativas, su imaginación, desarrollar su inteligencia emocional, dotarlos de capacidades intelectuales para reflexionar críticamente sobre su realidad y permitirles reconocer su propia autonomía y libertad, se están garantizando sus derechos a la educación y a la cultura, al mismo tiempo que sus demás derechos ciudadanos (Unesco, 2006).

Lamentablemente, y a pesar de la promulgación del derecho a la educación y a la educación artística, el escenario denunciado por la relatora no ha cambiado hasta hoy, debido a que muchas de las reformas educativas emprendidas por varios gobiernos del mundo en todos los niveles de enseñanza continuaron marginando e impidiendo el acceso a la educación de muchas comunidades, particularmente con la erradicación de materias y carreras humanistas o relacionadas con las artes, con el propósito de enfatizar el desarrollo de capacidades utilitarias en los estudiantes, que favorezcan el crecimiento económico mediante la generación de riqueza a través de la renta, y no en el cultivo de valores democráticos igualmente decisivos para el bienestar de las personas y el logro de justicia social (Nussbaum, 2010).

Para expertos sobre el tema, Colombia ha sido uno de esos casos en donde las reformas educativas no han garantizado la enseñanza artística y humanística en todas sus dimensiones, ya que las políticas públicas implementadas sobre este tema particular, en vez de contrarrestar y resolver dicha inequidad, la han agudizado (De Zubiría, 2015). Estas aseveraciones nos obligan a estudiar con juicio académico los esfuerzos gubernamentales para garantizar el derecho a la educación y a la cultura en el país, para que, desde una perspectiva científica, se pueda comprender a profundidad los factores generadores de esta injusticia social. Pero ¿̇cuáles han sido las estrategias llevadas a cabo por los gobiernos para que el Estado y sus instituciones no hayan podido resolver esta tensión que enfrenta la educación y la cultura?, ¿cómo han buscado, entonces garantizar el derecho a la educación y a la educación artística a sus ciudadanos?, y — sobre todo— ¿realmente han sido tan desastrosas las políticas públicas implementadas por los últimos gobiernos para garantizar estos derechos de manera plena y equitativa?

Entre los años 2002 y 2007, el Ministerio de Cultura de Colombia realizó varios estudios para evaluar el estado de la educación artística en el país, cuyos resultados no fueron positivos (Ministerio de Cultura de Colombia, 2007a). Un bajo porcentaje de docentes en artes con respecto a otras asignaturas, pocos programas de educación artística ofertados, el reducido presupuesto nacional para esta formación y la poca claridad legislativa para articular este campo del conocimiento entre niveles educativos fueron las conclusiones 
primordiales de estos estudios $^{[1]}$ (Ministerio de Cultura de Colombia, 2005). Debido a esto, el Ministerio de Cultura en alianza con el Ministerio de Educación Nacional, y en el marco del Plan Nacional de Educación Artística 2007-2010 (en adelante, PNEA 2007-2010), realizó varios acuerdos internacionales, convenios con organizaciones civiles, convenciones, seminarios y foros educativos para difundir las políticas formuladas hasta el momento, en aras de fortalecer este campo del conocimiento en el país (Ministerio de Cultura de Colombia, 2010a). Una de estas actividades realizadas por el Ministerio de Educación Nacional fue el Foro de Educación Artística y Cultural: El Arte y la Cultura fortaleciendo Competencias Básicas y Ciudadanas, llevado a cabo en el Centro Alférez Real de la ciudad de Cali en 2008, donde se reconocieron veinticuatro (24) experiencias significativas de educación artística de instituciones formales y no formales de todas las regiones del país, y de las cuales solo tres (3) correspondieron a la ciudad de Bogotá ${ }^{[2]}$ (Ministerio de Educación Nacional de Colombia, 2008a).

Entre muchas reflexiones y conclusiones que dejó ese foro, sus participantes señalaron primordialmente la urgente necesidad de diseñar currículos más funcionales y mejor articulados para poder brindar una educación artística de mejor calidad (Ministerio de Educación Nacional de Colombia, 2008a). Por ello, el Ministerio de Educación Nacional (2010), años más adelante, y en el marco del PNEA 2007-2010, elaboró las Orientaciones pedagógicas para educación artística en básica y media, con el propósito de facilitar y mejorar las condiciones de la enseñanza artística de este nivel educativo en los colegios del país (Ministerio de Cultura de Colombia, 2007b). Estos lineamientos se basaron en la flexibilización curricular como la estrategia primordial que les permitiría a los colegios adaptar sus planes de estudios y métodos pedagógicos a una enseñanza artística que cumpliera con los estándares de calidad y de pertinencia establecidos por la ley, como también a las demandas políticas, sociales y culturales de algunos sectores de la sociedad que exigían la garantía equitativa de este derecho universal (Minsterio de Educación Nacional de Colombia, 2010). Sin embargo, desde la implementación del PNEA 2007-2010, no se ha hecho un seguimiento riguroso ni continuo de esta política pública por parte de estos dos ministerios o de alguna organización civil que haya sido encargada para evaluar y confirmar si esta estrategia ha podido reducir la desigualdad en el acceso, goce, calidad y pertinencia de la enseñanza artística en Colombia, así como dar cuenta del estado de dichas experiencias y de sus alcances educativos, sociales, políticos y culturales hasta el día de hoy (Ministerio de Educación Nacional de Colombia, 2017a).

El presente artículo resume una investigación realizada entre los años 2016 y 2018, para evaluar la efectividad de la política pública de flexibilización curricular que se implementó hace 10 años en el país, con el propósito de mejorar la inclusión y la calidad de la enseñanza en los colegios de Colombia, centrándose en determinar si esta estrategia pedagógica, académica, administrativa y de gestión ha sido eficaz para garantizar el derecho a la educación artística en condiciones de equidad. Se trata de un estudio riguroso sobre el estado actual de las 3 primeras experiencias significativas de educación artística que fueron reconocidas en Bogotá y en la más reciente investigación sobre el impacto de una política social de esta naturaleza en la educación artística del país, al conocer y describir las formas de organización de estas comunidades escolares, el proceso llevado a cabo en cada una de ellas para implementar dicha política, los alcances pedagógicos para que fueran reconocidas como exitosas por el Ministerio, su capacidad de réplica en otras instituciones y, primordialmente, el análisis de la forma y el sentido en que se diversificó el currículo de educación artística para garantizar o no, este derecho universal en condiciones de equidad.

Además, la ministra de educación Yaneth Giha Tovar (2016-2018) presentó el 11 de octubre de 2017, el Plan Nacional Decenal de Educación 2016-2026, “El camino hacia la calidad y la equidad”, con el cual el gobierno nacional espera mejorar el sistema educativo durante los próximos años para dinamizar la movilidad social y reducir así las desigualdades sociales y económicas que padecen los colombianos (Ministerio de Educación Nacional de Colombia, 2017b). En su presentación, la funcionaria pública explicó que las estrategias formuladas para mejorar la calidad de la educación en dicho documento giran en torno a cinco (5) principios orientadores: 1) contribuir con la construcción de la paz, la cultura ciudadana y el sentimiento 
de Nación, 2) impulsar el desarrollo humano, la sostenibilidad y la equidad de la educación, 3) reducir los altos niveles de inequidad y las brechas regionales, 4) Ampliar los temas educativos en todos los ámbitos del Gobierno y la sociedad, y 5) entender la educación como una responsabilidad de la sociedad en su conjunto (Ministerio de Educación Nacional de Colombia, 2017b).

De igual manera, la ministra indicó que el Plan Decenal describe diez (10) grandes retos que deben ser superados a través de políticas públicas para tener un sistema educativo que cumpla con los propósitos mencionados anteriormente, y entre los cuales destacamos los tres (3) primeros por estar vinculados directamente con la política educativa de flexibilización curricular, que son: 1) regular y precisar el alcance del derecho a la educación, 2) la construcción de un sistema educativo articulado, participativo, descentralizado y con mecanismos eficaces de concertación, 3) el establecimiento de lineamientos curriculares generales, pertinentes y flexibles, 4) la construcción de una política pública para la formación de educadores, 5) impulsar una educación que transforme el paradigma que ha dominado la educación hasta el momento, 6) impulsar el uso pertinente, pedagógico y generalizado de las nuevas y diversas tecnologías para apoyar la enseñanza, la construcción de conocimiento, el aprendizaje, la investigación y la innovación, fortaleciendo el desarrollo para la vida, 7) construir una sociedad en paz sobre una base de equidad, inclusión, respeto a la ética y equidad de género, 8) dar prioridad al desarrollo de la población rural a partir de la educación, 9) aumentar la importancia otorgada por el Estado a la educación, incrementando la participación del gasto educativo en el PIB y en el gasto del Gobierno en todos sus niveles administrativos, y 10) fomentar la investigación para generar conocimiento en todos los niveles de la educación, (Ministerio de Educación Nacional de Colombia, 2017a).

Principios y retos que, sin duda alguna, determinarán las condiciones en que las instituciones educativas deberán garantizar el derecho a la educación artística equitativamente, por medio de la flexibilidad curricular en los años venideros. Por estas razones, el objetivo primordial de esta publicación es presentarle a la comunidad académica y profesional los resultados de la investigación titulada El currículo flexible en la educación artística bogotana: ¿una experiencia de Equidad o Inequidad?, para que sean discutidos por maestros artistas, directores escolares, padres de familia, investigadores sociales y formuladores de políticas públicas, al tiempo que son contrastados con la información existente en la literatura especializada sobre justicia social, descentralización educativa, flexibilidad curricular, derechos culturales, el derecho a la educación artística y de la qquidad en educación, con el propósito de fortalecer el debate público con conocimientos actualizados sobre enfoques teóricos, técnicos y legales propicios para mejorar el diseño, la implementación y la evaluación de políticas públicas de educación y cultura que garanticen estos derechos fundamentales en condiciones de verdadera equidad.

A continuación, se describe brevemente la metodología implementada en esta investigación para que el lector se entere, en un primer lugar, de cómo se orientó y estructuró conceptualmente el estudio, cómo se realizó el trabajo de campo y cómo fueron analizados los datos recopilados. Posteriormente, se da a conocer el marco conceptual de la investigación, para comprender las razones que justifican la adopción de los principios de justicia de Rawls y el enfoque de las capacidades en estos casos, para dimensionar los resultados obtenidos y valorar las conclusiones a las que llegó este estudio.

\section{Metodología}

El principal interrogante que se propuso resolver esta investigación sobre la política pública de flexibilidad curricular en relación con el logro de justicia social fue si los currículos flexibles de educación artística de los colegios públicos y privados de Bogotá, reconocidos como experiencias significativas por el Ministerio de Educación (2008a), han contribuido a garantizar el derecho a la educación artística de manera equitativa. Este cuestionamiento se planteó suponiendo que los currículos flexibles garantizaron la igualdad de oportunidades en el acceso a la enseñanza artística, en su aprendizaje, en el trato entre docentes y estudiantes, en el desarrollo 
de sus capacidades, en los resultados escolares y en las estrategias de inclusión social de los estudiantes de grado sexto a undécimo de las experiencias significativas estudiadas, a través de una articulación curricular que se orientó al desarrollo de competencias básicas y específicas de educación artística, para proteger y promover la diversidad de expresiones artísticas y culturales, y solucionar las contingencias que afectaron la equidad de oportunidades.

Por estas razones, el objetivo general de la investigación fue analizar la contribución de los currículos flexibles de educación artística a la garantía del derecho a la misma en Bogotá, a partir del estudio de las experiencias de los colegios bogotanos cuyas propuestas fueron reconocidas como significativas por el Ministerio de Educación Nacional, fundamentándose en la consecución de (3) tres objetivos específicos que fueron: 1) conocer cómo dichos currículos habían sido ideados y cómo se fueron adaptando a las realidades sociales e institucionales de cada experiencia significativa para lograr el reconocimiento del Ministerio, 2) identificar las diferencias y similitudes encontradas entre cada uno de los casos, y determinar qué tanto las flexibilidades curriculares garantizaron el derecho a la educación artística a sus estudiantes, con respecto a las categorías y subcategorías de investigación surgidas del supuesto anterior y del marco teórico de la investigación, y 3) recoger y analizar los aprendizajes sociales y académicos de cada colegio sobre la implementación de esta política pública para determinar los aspectos negativos y positivos de la flexibilidad curricular, que impidieron o permitieron garantizar la igualdad de oportunidades en educación artística.

Planteado esto, se procedió a encausar los objetivos de la investigación en las tres (3) experiencias significativas de educación artística formales que fueron reconocidas en Bogotá por el Ministerio de Educación Nacional (2008b):

1) El Carnaval Soloriental, realizado por los colegios distritales La Belleza-Los Libertadores, Nueva Delhi y Los Soches. Tres (3) instituciones educativas públicas que están ubicadas en la localidad de Usme y en la periferia del sur de la ciudad, que reciben a niñas, niños y jóvenes de estratos socioeconómicos 0,1 y 2 , mayoritariamente (Secretaría de Educación del Distrito, 2015a), y que conformaron una alianza cooperativa interinstitucional para garantizar la mejor utilización de los recursos económicos y profesionales en la realización de la experiencia artística (Ministerio de Educación Nacional de Colombia, 2008b).

2) El énfasis en educación artística de la Escuela Normal Superior Distrital María Montessori. Esta segunda propuesta pedagógica fue realizada por una escuela normalista, y por lo tanto pública, que está ubicada en la localidad Antonio Nariño en el centro de la ciudad, la cual prepara a estudiantes de estratos socioeconómicos 2 y 3, mayoritariamente, con diversos apoyos económicos y profesionales del Distrito para que puedan llevar a cabo su vida profesional como maestros a nivel nacional (Secretaría de Educación del Distrito, 2015b).

3) La Educación Artística, una experiencia longitudinal de un área del conocimiento en el Colegio Rochester. Esta última propuesta pedagógica fue realizada por una institución educativa privada, ubicada al norte de la periferia rural de la ciudad que cuenta con numerosas certificaciones, recursos económicos y profesionales para formar a niños, niñas y jóvenes de estratos socioeconómicos 5 y 6 (Colegio Rochester, 2017).

Posteriormente, se procedió a identificar en los casos de estudio, los documentos institucionales relacionados con las experiencias significativas y los sujetos que eran responsables directos de su realización (creadores, directores, coordinadores académicos y profesores), así como a sus beneficiarios (exalumnos), para saber, primero, cómo la flexibilidad curricular le había permitido a cada uno de ellos realizar las experiencias artísticas en sus colegios; segundo, comprender los alcances y limitaciones que tuvieron en su práctica pedagógica para garantizar equitativamente el derecho a la educación artística; tercero, conocer cuál fue su acogida por parte del estudiantado; y cuarto, analizar las diferencias y semejanzas encontradas entre los casos de estudio con base en criterios formulados por expertos académicos y profesionales sobre el tema. Por estas razones, se realizó un estudio de casos múltiple, comparado bajo un enfoque cualitativo de corte retrospectivo y transversal, que permitió interpretar la información recopilada a partir de textos y entrevistas en las cuales se trataron los antecedentes y el estado actual de cada caso de estudio, desde su creación hasta la 
fecha, para posteriormente comparar sus trayectorias y analizarlas a la luz del marco conceptual y las categorías de investigación propuestas en este trabajo académico.

Después, se configuró la población objeto de estudio, constituida por veinticinco (25) actores políticos, académicos y sociales, tales como funcionarios públicos del Ministerio de Educación Nacional y del Ministerio de Cultura, expertos académicos en educación artística, directores escolares, coordinadores académicos, docentes de arte y exalumnos de los siguientes colegios: 1) Rochester, 2) La Escuela Normal Superior Distrital María Montessori, 3) La Belleza-Los Libertadores, y 4) Nueva Delhi (El colegio Los Soches fue clausurado). ${ }^{[3]}$ Todos ellos relacionados con las tres (3) experiencias significativas de educación artística Bogotanas entre los años 2000 al 2018, y con los cuales se configuraron dos (2) grupos muestrales de carácter no probabilístico y teórico: el primero, constituido por funcionarios públicos y expertos en educación artística; y el segundo, muestreo de casos-tipo, compuesto por los directores, coordinadores de área, docentes de artes y exalumnos de cada colegio.

Este proceso investigativo fue planificado y realizado en ocho (8) etapas distintas: en la primera, se realizó un acercamiento y coordinación con los colegios y sus directivas escolares para conocer las experiencias significativas en artes; en la segunda, una revisión de las publicaciones sobre estas experiencias en el Ministerio de Educación Nacional, de Cultura y otras instituciones públicas y privadas; en la tercera, se realizó la observación participante de las actividades de formación artística en cada uno de los colegios responsables de estas experiencias significativas; en la cuarta, un ajuste de los instrumentos de recolección de datos con base en la revisión documental y la observación participante realizada; en la quinta, la recolección y caracterización de la información, donde se acopiaron (375) respuestas o datos testimoniales obtenidos a través de los instrumentos elegidos para dicho propósito y a los cuales se les asignó una valoración positiva si mostraban el logro pleno de los criterios de equidad propuestos por cada una de las subcategorías de investigación, o negativa si no los cumplían a cabalidad; en la sexta etapa, se realizó el análisis e interpretación de los datos codificados, comparando los resultados de cada categoría de investigación a la luz del enfoque de las capacidades como paradigma del desarrollo humano, mediante 3 matrices analítico-descriptivas a niveles de estudio micro, meso y macro; en la séptima, se hizo la devolución y validación de los resultados obtenidos de los profesores y directivas de los colegios estudiados; y en la octava, la elaboración del informe final, sus conclusiones y la divulgación del estudio.

Las fuentes de recopilación de datos a las que se acudió durante la investigación fueron los guiones elaborados para las entrevistas presenciales, que fueron grabadas digitalmente, y documentos como planes de estudio, registros visuales, audiovisuales y multimediales de los proyectos artísticos que guardaban los colegios estudiados o los mismos responsables. También, material bibliográfico de la Secretaria de Educación del Distrito, del Ministerio de Educación, del Ministerio de Cultura, del Instituto de Investigación Educativa, del Instituto de Desarrollo Pedagógico del Distrito (Idep), y de Bibliotecas y bases de datos. En cuanto a las técnicas implementadas durante la etapa de recolección de datos, estas fueron: 1) entrevistas abiertas y semiestructuradas, 2) análisis documental y 3) observación participante de las locaciones y de las clases de arte a las que se tuvo acceso. Todos los datos recopilados fueron codificados a partir de las categorías establecidas para la investigación de forma abierta y axial, así como con base en las categorías que emergieron a lo largo de la investigación. Aun así, fue necesario relatar en forma robusta cada caso de estudio para luego, desde la perspectiva teórica escogida, compararlos entre sí, identificando mediante la tabla de verdad, las similitudes y diferencias, así como, las condiciones suficientes y necesarias que fueron importantes en la garantía del derecho a la educación artística.

Sobre el marco conceptual de la investigación, es necesario mencionar que se estructuró con respecto a los conceptos o categorías fundamentales que constituyeron teóricamente el estudio, a saber: el currículo flexible, el derecho a la educación artística, y la eequidad para educación artística en básica y media. Cada una de ellas con una naturaleza disciplinaria diferente y compleja, que obligó a tener 3 abordajes diferentes y simultáneos: uno curricular, otro sobre características del derecho y un último sobre libertades y capacidades 
para el logro de la Equidad. Estas tres categorías se explicaron a partir del estudio de fuentes bibliográficas primarias, y se interrelacionaron con subcategorías identificadas en la literatura especializada, para orientarlas bajo dos (2) enfoques teóricos sobre la justicia que se inscriben en el marco del Liberalismo Político: la justicia como equidad de John Rawls y el enfoque de las Capacidades de Amartya Sen (Calvo, 2017). Este último profundizado por Martha Nussbaum (1947) como una teoría parcial de la justicia fundamentada en la idea de vida buena para todas y cada una de las personas, con la dignidad como criterio normativo (Calvo, 2017). De esta manera, se comprendió en la investigación a la equidad en educación artística como un imperativo ético que las instituciones educativas deben lograr brindar para garantizar dignamente este derecho y el desarrollo pleno de las capacidades de los estudiantes.

La primera categoría del marco conceptual, denominada el curriculo flexible, se estructuró con base en tres (3) subcategorías que se encontraron estratégicas para indagar si las divergencias que presentaron los currículos de Educación artística estaban en concordancia con las orientaciones pedagógicas para educación artística que publicó el Ministerio de Educación Nacional en 2010, que fueron: 1) articulación de componentes educativos en torno a la educación artística, 2) desarrollo de competencias básicas y específicas de educación artística, y 3) manejo de la tensión causada por la exclusividad de la apreciación artística y/ o la apropiación de la obra artística por el estudiante. La segunda categoría de investigación, el derecho a la educación artística, se organizó con base en cuatro (4) subcategorías basadas en el Esquema de las 4 Aes de Katarina Tomasevski, para determinar cuál era el estado de las siguientes características de este derecho garantizadas por el Estado en cada caso de estudio: 1) asequibilidad, 2) accesibilidad, 3) adaptabilidad y 4) aceptabilidad. Y la tercera categoría del marco conceptual, la equidad en educación artística para básica $y$ media, se constituyó con base en seis (6) subcategorías que se encontraron fundamentales en los debates sobre Equidad basados en los principios de justicia de John Rawls y en el enfoque de las Capacidades de Sen y Nussbaum, que fueron: 1) igualdad de oportunidades en el acceso a la enseñanza artística, 2) igualdad de oportunidades en el aprendizaje artístico, 3) igualdad de oportunidades en el tratamiento (entre el docente y el estudiante), 4) igualdad de oportunidades en el desarrollo de capacidades artísticas, 5) igualdad de oportunidades en los resultados escolares, y 6 ) igualdad de oportunidades en las estrategias de inclusión social.

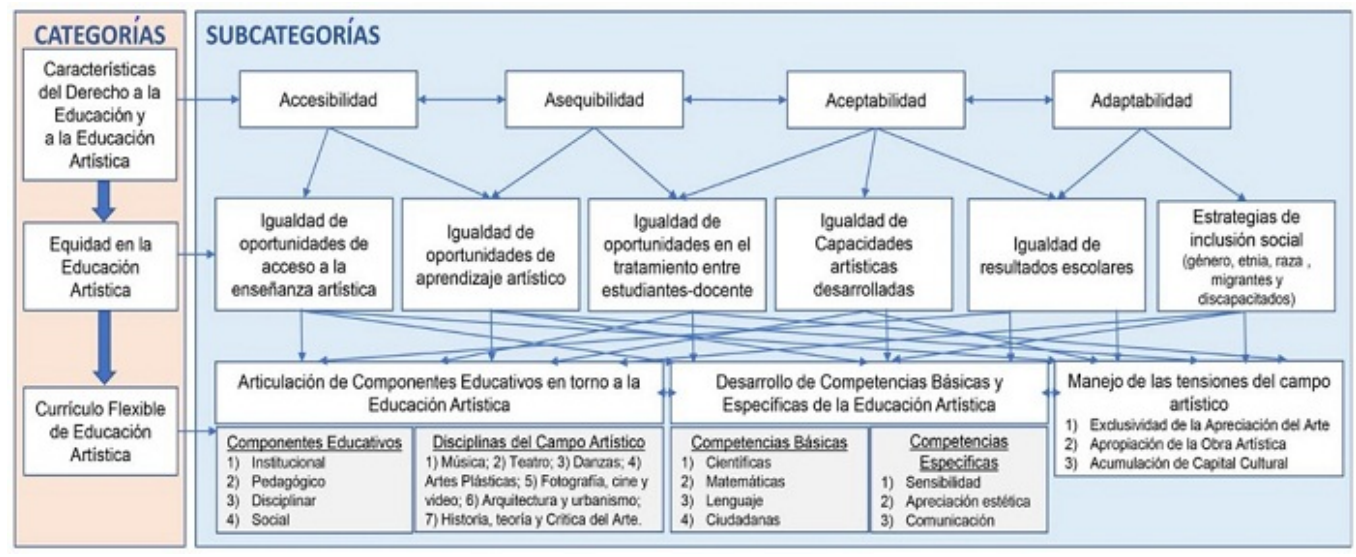

FIGURA 1.

Diagrama relacional de las categorías y subcategorías de la investigación para la comprensión de la metodología Fuente: elaboración propia

Por último, es importante mencionar que este arquetipo de categorías y subcategorías permitió aproximarse a profundidad en cada caso de estudio para describir y comprender el contexto interno y externo de cada experiencia significativa con respecto a la flexibilidad curricular, el derecho a la educación artística y la equidad, en un primer momento, y luego, analizar y diferenciar los datos obtenidos en cada experiencia significativa para determinar si cada propuesta curricular se orientó a garantizar la igualdad de oportunidades 
para la educación artística en estas dimensiones, y si se disminuyó la brecha existente de oportunidades entre los casos de estudio.

\section{¿Qué es el currículo flexible?}

Este concepto curricular surgió durante la década de los setenta del siglo XX, cuando los teóricos de la pedagogía detectaron problemas en los planes de estudio y en los sistemas educativos del hemisferio occidental, por tener un carácter pedagógico estático y una enseñanza orientada a la memorización de conocimientos enciclopédicos, que impedían brindar una educación adecuada a las nuevas demandas científicas, laborales, comerciales, sociales y políticas que exigía el mundo en ese entonces (Escalona, 2008):

Si a principios del siglo XX se presentó una revolución en el funcionamiento de los sistemas de producción, que condujo a la
reformulación del modelo taylorista (Torres, 1994) y a su enriquecimiento con los aportes fordistas de la racionalización en
la organización del trabajo en sus aspectos fundamentales, a partir de la década de los años setenta estos modelos comenzaron
a dar muestras de agotamiento al no acomodarse con facilidad a los nuevos mercados. Para Torres (1994), esto condujo
a un acelerado proceso de intercomunicación e interdependencia -o globalización- de las economías de los países que
transformaron las reglas de competitividad y obligó a revisar, modificar y a hacer más flexibles los procesos económicos. (Díaz,
2002, p. 46)

Además, este modelo rígido de educación masiva empezó a chocar con las ideologías individualistas, las necesidades de reconocimiento de los sujetos, el aumento de la migración global y la creciente demanda de garantías de los derechos humanos por parte de las minorías, lo que obligó a las escuelas a que buscaran adaptarse a las características de las personas y no a las de un grupo escolar determinado (Castillo et al., 2015). Debido a esto, aparecieron diversas propuestas desde la pedagogía, orientadas a flexibilizar los currículos para solucionar los problemas del modelo educativo, entre las cuales sobresalieron las latinoamericanas por basarse en las pedagogías críticas ${ }^{[4]}$, una corriente de pensamiento que consideró el currículo no como un producto terminado, sino como un instrumento en constante construcción que permitiría responder pedagógicamente a las necesidades históricas y culturales de los sujetos (Castillo et al., 2015).

Años más tarde, Donald Lemke (1981) recogió todas estas intenciones y, apoyado en la filosofía y en la psicología, elaboró una propuesta de currículo flexible que diferenciaba los procesos de enseñanza de los de aprendizaje, de la siguiente manera: el primero fue descrito como un proceso ordenado a través del cual un individuo le transmite o inculca a otro sus conocimientos, destrezas y habilidades (Castillo et al., 2015), mientras que el segundo, lo entendió como el proceso de recepción e internalización en el que intervienen fuerzas activas que influyen o transforman la perspectiva individual de cada sujeto y, por ende, su percepción de la realidad (Castillo et al., 2015).

Esta distinción facilitó pasar de un currículo centrado en la enseñanza a uno que también podía hacer énfasis en los procesos de aprendizaje, pero especialmente permitió que el agente principal que direcciona estos procesos no fuera el docente, sino la búsqueda de conocimientos nuevos por parte del estudiante para la compresión de un contexto real y específico (Lemke citado por Castillo et al., 2015). Por esta razón, Lemke propuso las unidades de aprendizaje integrado (UAI), que le permitirían al docente combinar contenidos de diferentes asignaturas en torno a las necesidades sociales, emocionales, físicas, morales y psicológicas del estudiante, e involucrarlo en la planificación del currículo tras realizar un diagnóstico de su aprendizaje (Castillo et al., 2015). Esto determinó que el currículo flexible no fuera lineal, permitiéndole a la triada docente-estudiante-aula de clase articularse entre sí de manera más fluida, así como con otros agentes escolares y con los contextos en donde se desenvuelven los sujetos para comprender mejor la realidad y los problemas que los rodean (Canton y Juste citados por Castillo et al., 2015).

A su vez, esta propuesta curricular ocasionó que la escuela fuera entendida de manera diferente, como una organización cuya misión es responder a las situaciones problemáticas de una sociedad, mediante la 
construcción continua de un currículo que facilite la interpretación, comprensión y reflexión de los conflictos sociales condicionados por factores políticos, económicos y culturales (Gimeno, 2010). En este sentido, el currículo flexible fue visto como una alternativa educativa que respondiera a este propósito al permitir que el aprendizaje, el individuo y su contexto fueran el epicentro de la actividad escolar, porque, por una parte, la sociedad moderna está en constante renovación y requiere que las instituciones educativas den respuestas a las expectativas, intereses y necesidades de las diversas poblaciones con conocimientos pertinentes; y, por otra, porque la variedad de estudiantes provenientes de culturas, etnias y religiones diferentes exige que la institución educativa busque brindar igualdad de oportunidades para la enseñanza y el aprendizaje en medio de la diversidad (Castillo et al., 2015).

Entonces, desde una perspectiva pedagógica, el currículo flexible según Lemke se caracteriza por orientar el aprendizaje del estudiante a través de la identificación de sus necesidades básicas, facilitar la exploración y comprobación de soluciones posibles a dichas necesidades, permitir reflexionar críticamente sobre un contexto determinado y realizar acciones que manifiestan la internalización y externalización de su pensamiento en relación con esa realidad (Castillo et al., 2015).

En el contexto colombiano, y desde una perspectiva institucional, el Ministerio de Educación Nacional entiende el currículo flexible teniendo en cuenta lo anterior, pero hace más énfasis en la inclusión social que en la pedagogía crítica, tal y como se puede apreciar en su definición:

El currículo flexible es aquel que mantiene los mismos objetivos generales para todos los estudiantes, pero da diferentes oportunidades de acceder a ellos: es decir, organiza su enseñanza desde la diversidad social, cultural, de estilos de aprendizaje de sus alumnos, tratando de dar a todos la oportunidad de aprender. (Ministerio de Educación Nacional de Colombia, 2005) $[5]$

Grupo Interdisciplinario de Investigación en Currículo, 2008a). Por ello, consideraron más apropiado definir el currículo flexible como un concepto multicomprensivo que exige ser entendido más allá de su equivocada interpretación como plan de estudios y como estrategia calificadora que facilita procesos de enseñanza-aprendizaje, porque hoy en día la flexibilidad curricular se entiende más como No obstante, para el Grupo Interdisciplinario de Investigación en Currículo (Ginic) de la Universidad de Antioquia, la definición objetiva de currículo flexible es una tarea compleja de resolver, porque es difícil de conceptualizar y llevar a la práctica debido a que las instituciones educativas en realidad están enfrentando un problema relacional más que pedagógico, dado que en la flexibilidad curricular están vinculados los individuos y sus comunidades, no solo con las escuelas, universidades, empresas, sociedades y culturas, sino también con principios curriculares como la interdisciplinariedad, la formación integral, la investigación, el acercamiento a otros campos disciplinares, las filosofías institucionales y las estructuras administrativas y normativas de cada institución (un principio fundamental de la política de transformación curricular, que como un tipo de currículo (Grupo Interdisciplinario de Investigación en Currículo, 2008b). Esta investigación inicialmente se enmarcó en la perspectiva teórica desarrollada por el Ginic para el análisis de referentes jurídicos sobre flexibilidad curricular, bajo la cual se entiende el currículo como un sujeto en sentido gramatical, facilitando la comprensión del término "flexible" como un adjetivo que lo determina (Grupo Interdisciplinario de Investigación en Currículo, 2008b).

Esta perspectiva analítica provee no solo un enfoque para estudiar los documentos institucionales y los testimonios de los directivos, docentes y estudiantes en relación con la flexibilidad curricular, sino también para sustentar por qué pueden existir currículos orientados hacia una formación más flexible que otros, y por qué algunos de ellos son entendidos como rígidos por carecer de vínculos con su entorno y con las tendencias pedagógicas contemporáneas (Grupo Interdisciplinario de Investigación en Currículo, 2008b). Además, este enfoque permitió comprender la forma en la que las concepciones curriculares de cada institución se relacionan directamente con las ideas que tiene su comunidad sobre la educación y escolarización, pero especialmente con el alcance social que se espera de ellas (Grupo Interdisciplinario de Investigación en 
Currículo, 2008a). Por ejemplo, haber considerado "el énfasis en funciones como la investigación, o en demandas de la economía o del estado, o en aspectos o componentes como el de las tecnologías que introduce necesariamente matices de diferenciación entre unas y otras visiones" (Grupo Interdisciplinario de Investigación en Currículo, 2008a, p. 13) terminó siendo relevante para comprender la flexibilidad curricular en una institución educativa en su búsqueda por lograr la equidad.

Dado el horizonte anterior, es importante delimitar, en primera medida, los significados de los términos curriculo y flexibilidad para comprender las múltiples formas en que se pueden articular entre sí, con otros conceptos como los ya mencionados, y con los alcances prácticos y sociales implicados en su descripción (Grupo Interdisciplinario de Investigación en Currículo, 2008a). En consecuencia, a continuación se describen brevemente las conclusiones a las que llegó el Grupo Interdisciplinario de Investigación en Currículo (2008b) sobre estos conceptos en la ley general de educación y en otros referentes jurídicos ${ }^{[6]}$, justificándolas con conceptos de la pedagogía y de la teoría curricular que se consideraron pertinentes, en aras de facilitarle al lector la comprensión del concepto de currículo flexible que se adoptó en esta investigación para el análisis de las tres (3) experiencias significativas de educación artística.

\section{El currículo}

Para Kemmis (1986), el currículo debe entenderse como un problema relacional entre la teoría y la práctica, por una parte, y entre la educación y la sociedad por la otra, porque es una construcción histórica generada bajo unas condiciones determinadas, tales como prácticas políticas, sociales y económicas, de producción de medios didácticos, prácticas, administrativas, de control, de supervisión del sistema educativo, etc. (Gimeno, 2010). Luego, entonces, el currículo no es solamente el texto que describe los contenidos, aspiraciones, intereses e ideales, y que regula las formas de enseñar y aprender según su misión en el contexto histórico, sino que también incluye las afectaciones de esa misma realidad contextual que lo condicionan y lo determinan como currículo oculto ${ }^{[7]}$, nulo ${ }^{[8]}$ o explícito ${ }^{[9]}$, sin ningún tipo de neutralidad, tales como la pobreza, el género, la clase social, entre otros (Gimeno, 2010).

Por su parte, la Ley General de Educación Nacional, ley 115, define el currículo como:

El conjunto de criterios, planes de estudio, programas, metodologías, y procesos que contribuyen a la formación integral y a la construcción de la identidad cultural nacional, regional y local, incluyendo también los recursos humanos, académicos y físicos para poner en práctica las políticas y llevar a cabo el proyecto educativo institucional. (Congreso de la República de Colombia, 1994, p. 17, artículo 76)

Para el Grupo Interdisciplinario de Investigación en Currículo (2008b), esta definición normativa describe un conjunto conformado por elementos teóricos y prácticos, así como por componentes educativos y organizacionales que son pertinentes para la realización del proyecto educativo de cada institución. Así mismo, resaltan que esta conceptualización expone un interés por generar espacios abiertos para la enseñanza en relación con la realidad de cada territorio, permitiendo pensar en la flexibilidad como un aspecto intrínseco del currículo que facilita la articulación de los elementos y componentes allí mencionados para que cada comunidad escolar brinde una educación integral y contribuya a construir la identidad cultural nacional (Grupo Interdisciplinario de Investigación en Currículo, 2008b). Sin embargo, esta definición solo orienta la conjunción de sus elementos al logro de identidad cultural nacional, sin mencionar otros conceptos también importantes para la educación integral y el proyecto educativo institucional, como pueden ser la igualdad social de la nación o el progreso económico del país, en tanto que:

Las condiciones culturales, el género y la pobreza son tres importantes fuentes de desigualdad que exigen intervenciones adecuadas para que el currículo se oriente por criterios de justicia social que favorezca la inclusión, más allá o previamente a su consideración como problema y propuesta de carácter cultural y pedagógico. (Gimeno, 2010, p. 15) 


\section{La flexibilidad}

En cuanto a la flexibilidad, hay que señalar que este término está relacionado con la capacidad de adaptación y de apertura, razón por la cual, se liga con la innovación, con los límites y con la diversidad de la otredad (Grupo Interdisciplinario de Investigación en Currículo, 2008c). Por esta razón, este término es comúnmente vinculado con acciones como doblarse, adaptarse, ajustarse y con otras acepciones que en el ámbito educativo se suelen relacionar con la facilidad para el cambio, para moverse, y con la propiedad para no perder la esencia, a pesar de los vínculos con el mundo diverso (García, citado por Grupo Interdisciplinario de Investigación en Currículo, 2008a). También, hay que tener en cuenta que la flexibilidad ha sido estudiada en la teoría y en la práctica en otros campos del conocimiento, especialmente el de la economía (Grupo Interdisciplinario de Investigación en Currículo, 2008a), donde se utiliza este término para referirse al esfuerzo de adaptación de las empresas y de los mercados nacionales a la globalización, entendida como el proceso resultante del aumento de las migraciones y del desarrollo de nuevas tecnologías de la información y de la comunicación que expanden y cambian dichos mercados, modificando las condiciones de empleabilidad y contratación, al deslocalizar la fuerza de trabajo (fenómeno del que proviene el termino flexibilidad laboral) (Díaz citado por Grupo Interdisciplinario de Investigación en Currículo, 2008a).

Por estas razones, fue fundamental para el Grupo Interdisciplinario de Investigación en Currículo (2008a) considerar dos clases de flexibilidad relacionadas con el currículo, y que son determinantes en el contexto escolar, las cuales, por cierto, surgen de analizar el ámbito universitario, pero que son aplicables en este estudio debido a que las prácticas docentes y formas organizacionales, que surgen y se desarrollan en la universidad, suelen ser replicadas en la educación básica y media (Huertas, 2010). La primera de ellas, según el Grupo Interdisciplinario de Investigación en Currículo (2008a), es la flexibilidad académico-pedagógica, la cual permite: a) una reorganización de las unidades académicas alrededor del conocimiento, b) un mayor énfasis en la comunicación, en la colaboración y en la movilidad entre los profesores, c) una mayor articulación de los cursos y programas académicos, d) una descentralización institucional que fortalece la autonomía para la realización de proyectos propios o integrados, e) un mayor control por parte del estudiante de su aprendizaje, f) la coexistencia de diferentes contextos de aprendizaje que facilitan la interacción y el acceso al conocimiento, g) nuevos espacios de aprendizaje condicionados por las nuevas tecnologías de la información, y h) la transformación de la relación vertical entre el profesor y el estudiante, a una más personalizada de carácter horizontal. Esto conlleva, según el Grupo Interdisciplinario de Investigación en Currículo (2008a), a "la apertura del escenario tradicional del aprendizaje, en particular, por vía del aprendizaje independiente y de la incorporación de las nuevas tecnologías" (p. 31), y comprender que "las formas de gestión y organización del conocimiento por parte de los docentes, puede facilitar u obstruir, según el caso, el establecimiento de la flexibilidad pedagógica" (p. 31).

La segunda es la flexibilidad administrativo-normativa, la cual se ha centrado más en la adecuación de enfoques y modelos de gestión requeridos por la globalización que en el manejo y control de la flexibilidad curricular por parte de la institución educativa, determinando y condicionando líneas de conducta y trabajo para sus estudiantes, docentes y directivos (Grupo Interdisciplinario de Investigación en Currículo, 2008a). Esta clase de flexibilidad se ha caracterizado por: a) el desarrollo de instrumentos normativos para asegurar la calidad y evitar la inequidad en el proceso de evaluación de la enseñanza, b) la internacionalización de la institución educativa con la vinculación de proveedores extranjeros de bienes y servicios escolares (de tres tipos: públicos, privado local y privado internacional) que condicionan la calidad de la enseñanza al estar compitiendo en un escenario global, c) el impulso de la educación virtual que impone nuevas prácticas pedagógicas a nivel presencial y no presencial, d) la formación de nuevas capacidades en los estudiantes, que ahora demanda la sociedad, e) el fortalecimiento de la financiación crediticia para mejorar el acceso de poblaciones económica e históricamente marginadas de la educación, y f) la ampliación de oferta 
educativa especializada con base en el desarrollo científico y la diversidad cultural (Grupo Interdisciplinario de Investigación en Currículo, 2008a).

Por todo lo anterior, se puede concluir que la flexibilidad curricular está relacionada con: 1) la apertura, adaptación y diversificación de los campos académicos, pedagógico, normativo y de gestión, 2) la reconfiguración de las relaciones y los límites tradicionales entre la institución y el entorno externo (local y global), 3) las disciplinas, áreas académicas y las funciones básicas de docencia, 4) la reorganización de los tiempos y espacios de la institución y de los estudiantes, así como de las trayectorias que establece la lógica de los contenidos y las que puede determinar cada uno de ellos siguiendo sus expectativas e intereses, 5) la educación general y la formación especializada, es decir, entre la educación media y la educación superior, y 6) el control y la autonomía, tanto del estudiante como de la institución educativa (Grupo Interdisciplinario de Investigación en Currículo, 2008a). Además, es plausible asumir que la flexibilidad curricular es el resultado de las condiciones de apertura y de cambio suscitadas por las transformaciones en la economía, las tecnologías, el conocimiento y las sociedades durante los últimos años, lo cual lleva a considerar la flexibilidad como una cualidad importante del diseño, la implementación y evaluación de los currículos para que las instituciones educativas puedan mantenerse vigentes en un escenario competitivo de continuo cambio (Grupo Interdisciplinario de Investigación en Currículo, 2008c). En consecuencia, la flexibilidad curricular en cada colegio es diferente, debido a que su comprensión, definición, alcance pedagógico y social puede variar en los distintos casos estudiados por las diferentes condiciones contextuales a las que están sometidas las instituciones educativas y sus estudiantes a nivel local, regional y global (Grupo Interdisciplinario de Investigación en Currículo, 2008a).

Por esta razón, en la investigación se consideró pertinente indagar la forma en la que las comunidades educativas estudiadas comprendieron la flexibilidad curricular, para conocer sus diferencias y similitudes, así como averiguar si su puesta en práctica garantizó, o no, el derecho a la educación artística de manera equitativa. Entonces, nuestro estudio entendió la flexibilidad curricular como una política educativa que le permite a estudiantes, docentes, directivos, padres de familia y empleados escolares adaptar, diversificar y velar ${ }^{[10]}$, de común acuerdo, por los criterios, planes de estudio, programas académicos, metodologías y procesos escolares, así como recursos físicos y temporales, para garantizar una experiencia de enseñanza y aprendizaje que satisfaga con justicia las necesidades del contexto histórico, tecnológico, económico, político y cultural de la nación, para llevar a cabo el Proyecto Educativo Institucional (en esta investigación, el derecho a la educación artística, particularmente).

\section{El derecho a la educación artística}

La situación descrita en la introducción de este artículo obligó a que organizaciones internacionales y nacionales como el Comisión Económica para América Latina y el Caribe (Cepal) y el Centro de Investigación y Educación Popular de Colombia (Cinep), entre muchas otras, asumieran durante la segunda década del siglo XX, un rol protagónico frente a los Estados del mundo y de la región, para defender el derecho a la educación como pilar fundamental del desarrollo social y económico de las naciones (Centro de Investigación y Educación Popular, 2006). Estas organizaciones expresaron que el derecho a la educación se inscribe en el marco de los derechos civiles, políticos, económicos, sociales y culturales (DESC), así como en los principios y las metas planteadas en las principales cumbres y convenciones internacionales, las cuales declaran que todos los niños y niñas tienen el derecho a recibir una educación libre, gratuita y de calidad, y señalaron a los gobiernos nacionales como los responsables de garantizar este derecho a lo largo de todas las etapas de la vida de los niños (Comisión Económica para América Latina y el Caribe, 2006). Reafirmaron, además, que la educación es un derecho humano que debe ser entendido en diversas dimensiones porque ocupa "un lugar importante en la lista de necesidades básicas junto con la salud, la alimentación, la vivienda 
y los servicios públicos, entre otros factores que determinan la calidad de vida de las personas en todos los países del mundo" (Centro de Investigación y Educación Popular, 2006, p. 9).

Así mismo, señalan que la importancia social de la educación radica en que es una actividad transformadora, fundamentada en un proceso comunicativo consciente de intervención sobre individuos y colectividades, con el fin de cumplir propósitos específicos, entre los cuales figura la formación y reproducción de determinados valores y formas de concebir el mundo (Centro de Investigación y Educación Popular, 2006). También, insisten en que el derecho a la educación brinda un componente democrático, que se constituye desde la posibilidad de participación de la comunidad en las decisiones en materia educativa, hasta el ejercicio de prácticas como el gobierno escolar que transversaliza las libertades básicas de los estudiantes para el libre desarrollo de sus capacidades y su formación ciudadana (Centro de Investigación y Educación Popular, 2006). Razones por las cuales, decisiones gubernamentales que cercenan la educación artística y humanística no solo atentan contra los derechos humanos, económicos, sociales, políticos y culturales de los pueblos y sus pactos convenidos, sino que truncan el desarrollo cognitivo, emocional, laboral, democrático y cultural de sus ciudadanos (Nussbaum, 2010).

Aunque la Ley General de Educación en Colombia establece, por medio del artículo 23, la enseñanza obligatoria de la educación artística en concordancia con el currículo y con el Proyecto Educativo Institucional de los colegios, en su desarrollo no hay una mención específica al derecho a la educación artística como sí la encontramos en el documento de la Unesco, lo cual no es un impedimento para exigir la garantía de este derecho porque en el país se cuenta con un marco legal que está conformado por la Constitución Política, en la que se reconoce el derecho a la educación en los artículos 27, 41, 67, 68 y 69, junto con el bloque de constitucionalidad que permite a "los tratados y convenios internacionales ratificados por el congreso que reconocen Derechos Humanos, prevalecer en el orden interno y tener carácter obligatorio para el Estado" (Centro de Investigación y Educación Popular, 2006, p. 65), junto con otros documentos jurídicos

${ }^{[11]}$ que permiten articular una demanda contra el Estado por el incumplimiento del derecho a la educación en todas sus dimensiones, incluyendo el derecho a la educación artística (Centro de Investigación y Educación Popular, 2006).

A pesar del respaldo jurídico normativo mencionado, Ariza (2017) señala que hay un desconocimiento generalizado sobre la importancia de la enseñanza artística en el contexto institucional de la educación en Colombia, y, más aún, en las practicas docentes, dado que en el ámbito escolar se relaciona más la educación artística con las manualidades, lo lúdico y lo recreativo, que con lo estético y los derechos civiles, económicos, sociales y culturales conducentes a una formación en ciudadanía democrática. Esto permite deducir de antemano que el reconocimiento del derecho a la educación artística probablemente sea también desconocido.

Por esta razón, fue fundamental para esta investigación enmarcarse en este desarrollo jurídico sobre el derecho a la educación y a la educación artística para señalar no solo los argumentos legales necesarios para garantizar estos derechos en Colombia, sino también que este marco legal incluye una red de diferentes tratados mediante los cuales los gobiernos determinan las obligaciones específicas para el cumplimiento del derecho a la educación. Bajo ellos se definieron unos estándares mínimos de aceptación que deberían estar vigentes en el país para facilitar su garantía, documentos que fueron tenidos en cuenta en esta investigación para saber cómo se garantizó el derecho a la educación artística en los casos de estudio (Tomasevski, 2004). Estos estándares mínimos de aceptación fueron elaborados por la relatora de los derechos humanos mencionada en la introducción, como un marco básico de obligaciones llamado el Esquema de las 4 Aes (Tomasevski, 2004), que los gobiernos deben utilizar para garantizar que la educación sea asequible, accesible, aceptable y adaptable para todos los ciudadanos. Estas características son descritas brevemente en la tabla 1 , con el propósito de explicar su aplicabilidad en esta investigación: 
TABLA 1.

Características del derecho la educación

\begin{tabular}{|c|c|c|c|}
\hline Asequibilidad & Accesibilidad & Aceptabilidad & Adaptabilidad \\
\hline $\begin{array}{l}\text { Esta característica engloba } \\
\text { dos obligaciones } \\
\text { gubernamentales diferentes: } \\
\text { la primera es el derecho a la } \\
\text { educación como un derecho } \\
\text { civil y político, el cual } \\
\text { requiere que el gobierno } \\
\text { permita cl establecimiento } \\
\text { de escuelas, mientras que el } \\
\text { segundo, el derecho a la } \\
\text { educación como derecho } \\
\text { social, económico y cultural, } \\
\text { requiere que el gobierno } \\
\text { asegure que la educación esté } \\
\text { disponible para todos los } \\
\text { ciudadanos en edad escolar } \\
\text { (Tomasevski, 2004). }\end{array}$ & $\begin{array}{l}\text { Esta segunda característica se } \\
\text { define de modo diferente } \\
\text { según los niveles educativos, } \\
\text { razón por la cual el gobierno } \\
\text { está obligado a asegurar el } \\
\text { acceso a la educación a todos } \\
\text { los ciudadanos en edad } \\
\text { escolar obligatoria, pero no } \\
\text { el acceso a la educación } \\
\text { secundaria o superior } \\
\text { (Tomasevski, 2004). }\end{array}$ & $\begin{array}{l}\text { Esta tercera característica } \\
\text { supone garantías de calidad } \\
\text { para la educación, estándares } \\
\text { mínimos de salud y } \\
\text { seguridad, requisitos } \\
\text { profesionales para los } \\
\text { maestros, que deben ser } \\
\text { estipulados, dirigidos y } \\
\text { controlados por el gobierno, } \\
\text { para promover la aceptación } \\
\text { del modelo de enseñanza en } \\
\text { la comunidad (Tomasevski, } \\
\text { 2004). }\end{array}$ & $\begin{array}{l}\text { Esta cuarta característica } \\
\text { exige que las escuelas se } \\
\text { adapten a los estudiantes de } \\
\text { acuerdo con el principio del } \\
\text { interés superior del niño, } \\
\text { revirtiendo la costumbre de } \\
\text { forzar a los estudiantes a que } \\
\text { se adapten a cualquier } \\
\text { escuela que se les ofreciera; } \\
\text { además, siendo los DD. HH. } \\
\text { indivisibles, el requisito de } \\
\text { adaptabilidad exige garantías } \\
\text { para que todos los demás } \\
\text { Derechos Humanos se } \\
\text { puedan enseñar y garantizar } \\
\text { en la educación } \\
\text { (Tomasevski, 2004). }\end{array}$ \\
\hline
\end{tabular}

Fuente: elaboración propia con base en características del derecho a la educación de Tomasevski (2004)

Lamentablemente, la Comisión Colombiana de Juristas (2004) denunció mediante un informe, el incumplimiento de las obligaciones básicas e inmediatas del derecho a la educación por parte de nuestro Estado, basándose en el esquema de las 4 Aes (Tomasevski, 2004) y haciendo especial énfasis en cómo los colegios amparados en el decreto 3020 del 2002 reorganizaron las plantas de personal docente y administrativo, al mismo tiempo que desmontaban la educación artística y otras asignaturas para poder cumplir únicamente con los estándares educativos exigidos por el Ministerio de Educación Nacional a principios del nuevo milenio. La presente investigación asume las características del derecho a la educación del esquema de las 4 Aes (Tomasevski, 2004) como subcategorías fundamentales para garantizar el derecho a la educación artística (ver tabla 2), con el propósito de indagar cuál es el estado actual de este incumplimiento estatal y cómo afectó a los colegios responsables de las experiencias significativas. 
TABLA 2.

Características del derecho a la educación artística

\begin{tabular}{|c|c|c|c|}
\hline Asequibilidad & Accesibilidad & Accptabilidad & Adaptabilidad \\
\hline Entendida en este estudio & Esta característica es & Entendemos esta & Esta última característica es \\
\hline como la disponibilidad de & entendida, en esta & característica como la & entendida como la \\
\hline recursos escolares & investigación, como las & aceptación que tiene la & capacidad de adaptación \\
\hline especializados para la & condiciones de acceso que & comunidad escolar & que tienen los espacios \\
\hline enseńanza artística (talleres, & brinda cada caso de estudio & (estudiantes, padres de & escolares (salones, talleres, \\
\hline materiales, salones, equipos, & para que los estudiantes & familia, profesores y & laboratorios y auditorios, \\
\hline etc.) y de las disciplinas del & puedan contar de manera & directivos) de las & incluidos sus equipos) y los \\
\hline campo artístico (música, & gratuita con los espacios y & condiciones de educación & tiempos de las actividades \\
\hline danza, teatro, cine, video, & tiempos destinados para la & artística que brinda la & académicas (horas \\
\hline dibujo fotografia, pintura, & educación artística escolar & institución, así como de los & curriculares y \\
\hline escultura, arquitectura y & mencionados & mecanismos de control & extracurriculares) para \\
\hline urbanismo) en los planes de & anteriormente, sin ningún & escolar que implementa & garantizar las otras \\
\hline estudio y en las actividades & tipo de restricción. & para asegurar la calidad y el & características del derecho a \\
\hline escolares en los casos de & & goce de la educación & la educación artística a los \\
\hline estudio, para asegurar una & & artística (evaluaciones & estudiantes, sin desmedro \\
\hline educación artística a sus & & docentes, estudiantiles, & de la integridad del campo \\
\hline estudiantes, sin obstáculos & & certificaciones, premios, & disciplinar y de la calidad de \\
\hline ni condicionamientos & & incentivos académicos $\mathrm{y}$ & la enseñanza artística \\
\hline políticos. & & laborales). & alcanzada por la institución. \\
\hline
\end{tabular}

Fuente: elaboración propia con base en características del derecho a la educación de Tomasevski (2004)

Para finalizar esta parte del marco conceptual, es importante recalcar que el propósito de haber adoptado el Esquema de las 4 Aes dentro de la base lógica y metodológica de esta investigación fue realizar una primera aproximación a la manera en que cada colegio estaba garantizando el derecho a la educación a través de estas cuatro características de obligatorio cumplimiento, pues partir de allí se facilitó valorar la forma en que cada institución educativa organizó, articuló y aprovechó sus recursos escolares para garantizar el derecho a la educación artística en su comunidad escolar en relación con su contexto externo, su flexibilidad curricular y los lineamientos gubernamentales ${ }^{[12]}$ para la educación artística.

\section{La Equidad}

En cuanto al término "equidad", hay que aclarar, en primer lugar, que suele ser asociado generalmente con justicia social, sin embargo, las implicaciones de esta relación no han sido lo suficientemente bien comprendidas en las discusiones públicas y académicas, porque su concepción se fundamenta e interactúa con otros tres conceptos de suma importancia a nivel político: la igualdad, la inclusión y el cumplimiento del derecho y la justicia (Bracho y Hernández, 2009). Esta compleja comprensión del término se debe a que durante las últimas décadas la equidad se ha vuelto relevante en el debate público porque la globalización y la migración han transformado las condiciones de vida de las personas, ampliando las brechas sociales y profundizando la pobreza, razón por la cual se espera que las reacciones de los gobiernos y los Estados para contrarrestar estos problemas no sean solo rápidas y efectivas, sino también sensibles, justas e incluyentes (Bracho y Hernández, 2009).

Para Bracho y Hernández (2009) las relaciones conceptuales existentes que tiene la equidad con la igualdad, la inclusión y el cumplimiento del derecho y la justicia se explican de la siguiente manera:

Equidad e igualdad son conceptos ampliamente interrelacionados, aun cuando el de equidad es más complejo al permitir por principio ciertas desigualdades. El concepto de equidad incluye un valor moral o ético para que un bien o servicio no sea distribuido igualitariamente, sino en beneficio de los sectores sociales más desfavorecidos. No obstante, la equidad también 
requiere que ciertos bienes sean distribuidos, inicialmente en proporciones iguales. En este sentido, equidad se relaciona con la justicia, ya que se argumenta que la distribución de los bienes debe realizarse de acuerdo con lo que cada quien merece. (p. 3)

Además, señalan sobre la relación entre equidad e igualdad en el ámbito educativo, que esta última es justificable porque todos los estudiantes tienen igual derecho a recibir una educación básica de calidad (Bracho y Hernández, 2009), ya que como se mencionó anteriormente, el derecho a la educación es igual para todos, y porque todos los alumnos son sujetos activos de iguales derechos y libertades (Bracho y Hernández, 2009). No obstante, aclaran que la única igualdad pertinente en educación es la de oportunidades, porque se considera acertada si se entiende como una forma de garantizar la igual dignidad, los mismos derechos y libertades para el logro de un igual derecho a la educación (Bracho y Hernández, 2009). Sobre las otras relaciones conceptuales de la equidad, los autores explican que:

\footnotetext{
La justicia se sustenta en el derecho, de manera que dado a que todos los sujetos son iguales ante la ley, nadie debe ser privado de lo que por derecho le corresponde. Así, la justicia utiliza como criterio práctico único la igualdad para regular la relación entre los particulares y la distribución de bienes. Por último, la exclusión social es la expresión más dramática de la inequidad; y se traduce en una alta concentración de riqueza, ingresos y escolaridad en unos pocos sectores, mientras que en otros prevalece la indigencia, el desempleo, y la falta de acceso a servicios públicos como la educación. La exclusión margina a ciertos grupos y genera una cadena que se transfiere de generación en generación, causando mayores desigualdades económicas, étnicas, sociales y de género (p. 3).
}

Luego, entonces, la igualdad, la inclusión y el cumplimiento del derecho y la justicia son principios estructurales y fundamentales del concepto de equidad, al permitir de manera interrelacionada no solo el logro de justicia social, sino también la libertad de elección de las personas para alcanzar lo que ellas valoran (Bolívar, 2005).

\section{La Equidad en educación básica y media}

Ortega (2003) señaló que la Cepal entiende la equidad como: "la igualdad de oportunidades de acceso, de tratamiento y de resultados, y liga al concepto de equidad el de eficiencia; y al de competitividad el de ciudadanía" (p. 130), argumentando que la equidad ya no se comprende solamente en la cobertura, sino también en la calidad de la oferta y en la eficacia de las estrategias implementadas para resolver el problema de los excluidos de la educación (Ortega, 2003). Por ello resaltan la importancia de desarrollar capacidades para la incorporación pertinente de las personas en las nuevas formas de producción y de participación pública (Ortega, 2003). Y concluye que "una política educativa en pro de la equidad tiene que establecer una relación inversamente proporcional entre las capacidades educativas preexistentes de un grupo determinado y la integralidad, duración e intensidad de la política que tiene como objetivo realizar dichas capacidades" (Ortega, 2003, p. 130)

Señala que la Unesco relaciona la educación con "una actividad sectorial sostenible y bien integrada, que está explícitamente vinculada con la eliminación de la pobreza y las estrategias de desarrollo" (Ortega, 2003, p. 131), razón por la cual enfatiza la urgencia de avanzar en el compromiso y la participación de la sociedad civil en la formulación, implementación y evaluación de estrategias que fomenten la educación, con el fin de consolidar su participación en la toma de decisiones, y promover la supervisión y el control de los recursos destinados para la enseñanza (Ortega, 2003).

Por su parte, la Organización de Estados Iberoamericanos (OEI) plantea que el debate público y académico sobre equidad en educación debería resolver, primero, cómo es una sociedad justa para luego poder determinar cuáles son los procesos educativos que facilitan su constitución (Organización de Estados Iberoamericanos, 2004). Y para ello, propone diferenciar y desarrollar las dinámicas que desarrollan autonomía, libertad y solidaridad, para determinar cuáles son los medios y los fines apropiados para fortalecer esas dinámicas a través de la educación, fijar el rol de los distintos actores (el Estado, el mercado y la sociedad civil) en ese proceso; y, 
por último, diferenciar los bienes a perseguir de los bienes a distribuir, sus modalidades de reparto y criterios para su acceso (Organización de Estados Iberoamericanos, 2004).

Entonces, se pudo concluir inicialmente que a pesar de las diferencias semánticas, estas organizaciones multilaterales entienden y promueven una definición de equidad para educación que involucra los conceptos mencionados anteriormente: la igualdad, la inclusión y el cumplimiento del derecho y la justicia. Por ello, esta investigación acogió los conceptos y preocupaciones de estas organizaciones sobre la equidad, para explorar de qué manera la flexibilidad curricular de las experiencias significativas en educación artística estudiadas contribuyeron o no a constituir una sociedad con procesos de enseñanza justos, teniendo en cuenta si esta política educativa favoreció la igualdad de oportunidades en el acceso, el tratamiento y los resultados escolares de los estudiantes; también, si desarrolló integralmente sus capacidades y fortaleció las dinámicas de producción, distribución y circulación de bienes y servicios para contrarrestar la pobreza y la exclusión en educación artística. Para esto, se adoptaron dos (2) enfoques teóricos sobre la justicia que se inscriben en el marco del Liberalismo Político, que son: La justicia como Equidad de John Rawls (1921-2002) y El enfoque de las Capacidades de Amartya Sen (1933), profundizado por Martha Nussbaum (1947), los cuales se consideraron pertinentes para abordar éticamente estas preocupaciones en la investigación, y cuya caracterización y justificación expondremos brevemente a continuación.

\section{Los principios de justicia en la teoría de John Rawls}

La justicia como equidad, propuesta por John Rawls como una concepción política (no moral ni metafísica) de la justicia, se vale de una idea organizadora fundamental: la de la "sociedad como un sistema justo de cooperación social entre personas libres e iguales, consideradas integrantes verdaderamente cooperadores de la sociedad durante toda su vida" (Rawls, 2011). Para Rawls, la sociedad es una asociación de personas más o menos autosuficientes, que son capaces de reconocer en sus relaciones ciertas normas de conducta como obligatorias, y cuya mayoría de ciudadanos está comprometida con ellas en la acción (Caballero, 2006). Estas normas configuran un sistema de cooperación planeado para promover el bien y facilitar la obtención de ventajas mutuas, que naturalmente, en una sociedad plural moderna, enfrentan conflictos entre variadas identidades e intereses (Caballero, 2006). Por esta razón, el objetivo primario de la justicia, según Rawls, es la configuración de una estructura básica de sociedad mediante la construcción deliberativa de principios de justicia (ver tabla 3), que determinan el funcionamiento de las instituciones ${ }^{[13]}$ que deben distribuir bienes sociales primarios ${ }^{[14]}$ para dividir con equidad las ventajas provenientes de la cooperación social y disminuir así la conflictividad (Caballero, 2006).

La idea principal de su teoría es que los principios de justicia, acordados entre personas racionales, que poseen dos poderes morales, "ser racionales" - tener una concepción del bien-y "razonables"-capacidad para tener un sentido de justicia ${ }^{[15]}$ - ciudadanos libres e iguales, en una situación contractual imparcial (denominada posición original), pueden contar con validez universal e incondicional (Caballero, 2006). Pero ¿cómo estar seguros de que la posición original conduce al logro de principios de justicia imparciales y no a otra clase de acuerdos? Rawls se responde esta pregunta acudiendo a dos conceptos para evaluar la equidad en los principios de justicia que son: el equilibrio reflexivo, un proceso de ajuste mutuo entre perspectivas particulares, que logra la concordancia entre las condiciones de la posición original, los juicios derivados de ella y los juicios morales ponderados (Caballero, 2006); y el velo de la ignorancia, que describe la restricción impuesta a las personas de saber con certeza cuáles serán sus posiciones futuras después del arreglo, queriendo indicar que la incertidumbre permite valorar los principios acordados como justos porque, si alguno de ellos ofreciera tranquilidad, significaría que fueron diseñados para la ventaja o desventaja de individuos particulares en un escenario específico (Caballero, 2006). A partir de esta lógica procedimental, Rawls propone dos 
principios de justicia básicos, candidatos a un consenso entrecruzado entre personas con versiones de vida buena plurales e inconmensurables (Caballero, 2006).

TABLA 3.

Principios de la teoría de justicia de John Rawls

\begin{tabular}{|c|c|}
\hline $\begin{array}{l}\text { Principio de igualdad de } \\
\text { oportunidades }\end{array}$ & Principio de la diferencia \\
\hline $\begin{array}{l}\text { Cada persona tiene igual derecho a } \\
\text { exigir un esquema de derechos y } \\
\text { libertades básicos igualitarios } \\
\text { completamente apropiado para sí } \\
\text { mismo, y que sea compatible con el } \\
\text { mismo esquema para todos. Y, en este } \\
\text { esquema, libertades políticas iguales que } \\
\text { tienen que ser garantizadas en su valor } \\
\text { (Rawls, 2011), "para superar las } \\
\text { desigualdades de los azares de la vida" } \\
\text { (Organización de Estados } \\
\text { Iberoamericanos, 2004, párr. 122) }\end{array}$ & $\begin{array}{l}\text { Las desigualdades sociales y económicas solo se } \\
\text { justifican por dos condiciones: en primer lugar, } \\
\text { estarán relacionadas con puestos y cargos abiertos a } \\
\text { todos, en condiciones de justa igualdad de } \\
\text { oportunidades; en segundo lugar, "estas posiciones y } \\
\text { estos cargos deberán ejercerse en el máximo beneficio } \\
\text { de los integrantes de la sociedad menos } \\
\text { privilegiados." (Rawls, } 2011 \text { p. 31) El principio de la } \\
\text { diferencia, restaura o disminuye de algún modo las } \\
\text { brechas existentes entre los diferentes puntos de } \\
\text { partida que tienen las personas en la sociedad } \\
\text { (Organización de Estados Iberoamericanos, 2004). }\end{array}$ \\
\hline
\end{tabular}

Fuente: elaboración propia con base en Rawls (2011) y la Organización de Estados Iberoamericanos (2004)

Martha Nussbaum (2014), en el marco del Liberalismo Político propuesto por Rawls, asume que todas las concepciones de sociedades justas están basadas en el reconocimiento de la igual dignidad de todas las personas porque todas ellas gozan del mismo valor, el cual es inherente o intrínseco a su propio ser, y no depende de su lugar en la sociedad, de su religión, etnia u opción de género. Sin embargo, encuentra dos tópicos no suficientemente trabajados por Rawls, y que requieren ser pensados para lograr la estabilidad social: en primer lugar, Rawls diseñó su teoría de la justicia para sociedades bien ordenadas, en las cuales típicamente los problemas de exclusión y estigmatización han sido resueltos (Nussbaum, 2014). Nussbaum, a partir de sus trabajos en la India, reconoce la existencia de sociedades decentes que aspiran a la justicia, en las cuales va a concentrar su interés, lo cual generará variaciones significativas en la propuesta normativa (Nussbaum, 2014). Consideramos que Colombia podría incluirse en esta categoría. En segundo lugar, la sociedad bien ordenada pensada por Rawls exige mucho a sus ciudadanos, por un lado, al permitir solamente las desigualdades de riqueza y renta cuando estas contribuyen a mejorar la situación de los más desfavorecidos (Nussbaum, 2014); y, por otro, dado que no todas las personas tienen el mismo compromiso con la igual libertad de todos los ciudadanos, se requiere un significativo esfuerzo en la formación de ciudadanos que apoyen las instituciones sociales en el tiempo, garantizando así la estabilidad de la sociedad (Nussbaum, 2014).

Por estas razones, Rawls, a diferencia de otros liberales, consideró la cuestión de las emociones, de una psicología moral razonable, como determinante de la sociedad justa. (Nussbaum, 2014). En efecto, en Teoría de la justicia de 1971, postula que emociones inicialmente cultivadas en la familia podrían desarrollarse hasta estar dirigidas a los principios de justicia, constituyéndose así en un respaldo real a las instituciones (Calvo, 2017). Sin embargo, en Liberalismo Político elimina todo lo relativo a esa psicología moral razonable, si bien insiste en que es absolutamente necesaria (Calvo, 2017). Ese es el otro vacío que Nussbaum se propone subsanar, mediante un estudio refinado, apoyado en la psicología cognitiva y en el psicoanálisis de las relaciones objetales, de las emociones humanas, de su carácter y posible cultivo como emociones políticas (Calvo, 2017). 
A juicio de Nussbaum (2014), el tipo de sociedad que aspira a la justicia y a la igualdad de oportunidades para todos tiene dos (2) retos imprescindibles que superar para el cultivo de emociones políticas que garanticen su realización: el primero es "la generación y sostenibilidad de un compromiso fuerte con proyectos valiosos que requieran esfuerzo y sacrificio" (Nussbaum, 2014, p. 15), orientada a la redistribución del bienestar, la inclusión social de grupos excluidos o marginados, la protección del medio ambiente, la colaboración multilateral y la defensa nacional (Nussbaum, 2014); el segundo es "mantener bajo control ciertas tendencias que acechan en todas las sociedades y, en último término, en el fondo de todos nosotros [...] a proteger nuestro frágil yo denigrando y subordinando a otras personas" (Nussbaum, 2014, p. 16), típicamente la repugnancia, la envidia, la ira y la vergüenza (Calvo, 2017). A partir de su teoría de las emociones, en la cual estas se caracterizan por tener contenido cognitivo, ser juicios de valor acerca de la vida buena que se desarrolla a lo largo de la vida del individuo y estar condicionadas por imaginarios y creencias sociales dominantes, se otorga un papel decisivo a la educación para la ciudadanía democrática y la formación moral de la sensibilidad, que invita a imaginar vías a través de las cuales las emociones apoyen los principios básicos de la cultura política de una sociedad imperfecta pero aspiracional, de manera que los ciudadanos coincidan y respalden normas básicas de igualdad de respeto para todos (Nussbaum, 2012). Propone como dispositivo privilegiado, el cultivo de las Humanidades y las Artes; en efecto, una manera de lograrlo es que el Estado le conceda espacios a los artistas para que expongan y se conozcan las diferentes visiones que existen de los valores políticos fundamentales en las sociedades (Nussbaum, 2010, 2014).

En el marco del Liberalismo Político, hemos visto cómo la configuración de una sociedad democrática estable se articula en dos pilares: instituciones inspiradas en principios de justicia que logren un consenso entrecruzado entre ciudadanos con visiones disímiles e inconmensurables de vida buena, y una educación centrada en cultivo de emociones proclives a la inclusión del otro diferente, al respeto por la igual dignidad de todos los seres humanos (Calvo, 2017). A seguir, expondremos los ejes de la teoría de la justicia propuesta por Martha Nussbaum, enmarcada en el enfoque del desarrollo humano propuesto por Amartya Sen, denominado Enfoque de las Capacidades.

\section{El enfoque de las Capacidades: Amartya Sen y Martha Nussbaum}

Para Nussbaum (2012) este enfoque, junto con el de Sen, se caracterizó como una aproximación temporal y particular a la evaluación del desarrollo de una sociedad, centrado, a diferencia del PIB, en el utilitarismo, mientras que el enfoque rawlsiano de distribución equitativa de bienes primarios, se enfoca en la calidad de vida de las personas concretas, y se convierte en una teoría parcial de la justicia social de carácter normativo, y candidata a lograr un consenso traslapado a nivel mundial. El enfoque sostiene que la pregunta central cuando se compara el desarrollo de las sociedades y se evalúan sus situaciones conforme a conceptos de dignidad o justicia social es: ¿qué es capaz de hacer y ser cada persona? (Calvo, 2017). Esta pregunta orientadora del enfoque permite concebir a cada una de ellas como un fin en símisma porque: 1) no se está buscando calcular el bienestar promedio del grupo social, sino las oportunidades que cada uno de sus miembros tiene para desarrollar integralmente sus capacidades humanas (Nussbaum, 2010), 2) porque considera a las capacidades como el conjunto de oportunidades con que cuenta cada persona para elegir y actuar, enmarcando el enfoque en la libre elección de posibilidades (Nussbaum, 2012), 3) porque es pluralista en lo relacionado con valores, al considerar que las capacidades que tienen una importancia central para las personas deben diferenciase cualitativa y no cuantitativamente, ya que no se pueden reducir a una escala numérica única, son diferentes e inconmensurables, aunque se mantengan en íntima relación (Nussbaum, 2012), 4) porque el enfoque se preocupa también por las desigualdades sociales arraigadas que causan injusticia, especialmente por aquellas que marginan o excluyen a determinadas personas de contar con el mismo conjunto de posibilidades que otra (Nussbaum, 2012) y 5) porque teniendo en cuenta todo lo anterior, el enfoque recalca el deber del Estado 
y de las políticas públicas de mejorar la calidad de vida de las personas según cada una de sus capacidades (Nussbaum, 2012). Así, la pregunta por la justicia en este enfoque está atravesada por la inquietud por la vida buena, por el reconocimiento de la necesidad que tienen las personas de tener igualdad de oportunidades para el desarrollo de capacidades, las cuales les permiten a todos y cada uno de los individuos realizar sus proyectos de vida de manera libre y digna (Nussbaum, 2012). Naturalmente, bajo este enfoque el desarrollo de una nación no puede identificarse con su crecimiento económico (Calvo, 2017).

Nussbaum (2012) considera de vital importancia el papel que desempeña la educación en todo proceso de desarrollo, no solo porque permite inculcar la idea de vida buena y digna, sino también porque gracias a ella las personas pueden empoderarse de capacidades combinadas ${ }^{[16]}$ y desarrollar sus capacidades internas [17]. Conceptos importantes en esta investigación porque permiten comprender la relación existente entre las capacidades desarrolladas o entrenadas de los estudiantes, con las posibilidades que se brindan a nivel interno o externo de la escuela, y que deben ser articuladas por una política de flexibilización curricular para garantizar que los estudiantes puedan realizar su proyecto de vida buena, a pesar de los obstáculos y dificultades que enfrenten al momento de graduarse, dado que: "una sociedad podría estar produciendo adecuadamente las capacidades internas de sus ciudadanos y ciudadanas, al tiempo que, por otros canales, podría estar cortando las vías de acceso de esos individuos a la oportunidad de funcionar de acuerdo con esas capacidades"(Nussbaum, 2012, p. 41).

Adicionalmente, Nussbaum (2012) destaca que su aporte al enfoque de las capacidades fue añadirle un carácter normativo, cuyo criterio es la dignidad humana; en concreto, establece un listado de 10 capacidades centrales para el logro de una justicia social básica que son: 1) vida (poder vivirla con normalidad), 2) salud física, 3) integridad física (vivir libres de agresiones), 4) sentidos, imaginación y pensamiento, 5) emociones, 6) razón práctica (poder formarse una concepción del bien), 7)afiliación (una interacción social libre), 8) otras especies (una relación armónica con animales y plantas), 9) juego, y 10) control sobre el propio entorno (participación política) (Nussbaum, 2012). De estas, solo se tuvieron en cuenta dos (2) capacidades centrales en esta investigación, por ser fundamentales para justificar la importancia de las Artes y las Humanidades para el logro de la equidad en educación básica y media, que son: 4) sentidos, imaginación y pensamiento, y 5) emociones.

Nussbaum (2012) señala que las Artes y las Humanidades dignifican la vida humana al desarrollar la sensibilidad, las emociones, la imaginación y el pensamiento crítico, cualidades fundamentales para la formación ciudadana y la constitución de una democracia deliberativa lo suficientemente comprometida con una cultura política respetuosa de las opciones de vida de cada persona. Considera importante la experiencia artística en la educación, fundamental para que las personas puedan desarrollar sus capacidades de manera sensible e integrada, puedan elegir y desarrollar la vida que desean con gusto, calidad y un bienestar digno (Nussbaum, 2012). Además, señala que al utilizar el enfoque de las capacidades en el ámbito educativo, se le debe prestar igual atención a la pedagogía y a los contenidos, preguntándose si los objetivos de los estudios y la naturaleza de las interacciones en el aula, en este caso el rol asignado al pensamiento crítico, a las emociones y a la imaginación en la educación artística, satisfacen los objetivos centrales del enfoque de las capacidades, especialmente en lo relacionado con la ciudadanía, porque una educación que es sensible al contexto, la historia, las circunstancias culturales y económicas, es garante efectivo del derecho a la educación (Nussbaum, 2012).

Bracho y Hernández (2009) afirman que es posible evaluar la posición social de los individuos en una sociedad basándose en dos criterios distintos: por un lado, se puede valorar la libertad que se tiene para alcanzar los objetivos que las personas se han propuesto y, por el otro, también se pueden valorar los objetivos alcanzados de manera efectiva, lo que quiere decir que se puede analizar la oportunidad real que tuvo una persona para lograr un propósito que consideraba valioso, y los objetivos que dicha persona buscó alcanzar. Entonces, esta valoración se puede realizar en el ámbito educativo, al identificar las oportunidades reales con que contaron los estudiantes para acceder al sistema, y así mismo aquellas habilidades efectivas y útiles que 
desarrollaron para la vida gracias a la educación recibida (Bracho y Hernández, 2009). A nuestro juicio, tanto el enfoque teórico de Rawls como el de Nussbaum permiten evaluar criterios de equidad en educación como lo mostramos en la tabla 4, que justifica la adopción de ambas perspectivas teóricas en este estudio.

TABLA 4.

Justificaciones para aplicar ambos enfoques teóricos en esta investigación

\begin{tabular}{|c|c|}
\hline Teoría de la justicia de Rawls & Enfoque de las capacidades \\
\hline $\begin{array}{l}\text { No concibe la educación como un mero problema privado que se resuelve en } \\
\text { el libre mercado, sino que la considera una cuestión de política pública que } \\
\text { es exigible como un derecho en términos de justicia (Organización de } \\
\text { Estados Iberoamericanos, 2004), permitiéndonos explorar las tensiones } \\
\text { existentes respecto al acceso de las personas a la educación (en nuestro caso, } \\
\text { a la enseñanza artística) desde un enfoque de derecho que relaciona los } \\
\text { ámbitos público y privado (Bolivar, 2005). }\end{array}$ & $\begin{array}{l}\text { Sostiene, en primer lugar, que el eriterio de justicia debe ser la igualdad } \\
\text { de capacidades desarrolladas en las personas, porque no solo en el acceso } \\
\text { a los bienes primarios (Rawls) está inmersa la libertad real de elegir los } \\
\text { modos de vida que se quieren, ni tampoco solo en el mero bienestar que } \\
\text { produce el uso de los bienes (utilitarismo), " lo que restringe la libertad a } \\
\text { un valor subjetivo o a uno económico (Organización de Estados } \\
\text { Iberoamericanos, 2004). Esta primera justificación nos permite valorar } \\
\text { las capacidades de la persona para transformar sus recursos en libertades } \\
\text { (Bolívar, 2005), facilitando el análisis de las experiencias de los } \\
\text { estudiantes, profesores y directores con respecto a este propósito. }\end{array}$ \\
\hline $\begin{array}{l}\text { Rawls define la justicia como equidad, y sosteniene, en términos generales, } \\
\text { que la sociedad es una agrupación de personas que buscan mejorar la } \\
\text { situación común, y por esta razón, su definición de justicia como equidad es } \\
\text { una noción pública de la justicia propia de una "sociedad bien ordenada". } \\
\text { (Organización de Estados Iberoamericanos, 2004, párr. 120). Esta } \\
\text { afirmación, nos permite indagar las nociones de equidad implementadas } \\
\text { para corregir o compensar las desventajas sociales (Bolívar, 2005) en el } \\
\text { acceso y goce de la educación artística en cada caso de estudio. }\end{array}$ & $\begin{array}{l}\text { Porque este enfoque no reduce el bienestar a lo que cada sujeto considera } \\
\text { como tal (oponiéndose a las versiones más difundidas del utilitarismo), } \\
\text { sino que busca cierto "criterio estandarizado y objetivado de bienestar" } \\
\text { (Organización de Estados Iberoamericanos, 2004, párr. 166) que } \\
\text { permita establecer comparaciones intersubjetivas para generar criterios } \\
\text { distributivos vinculados a la equidad como fundamento de justicia } \\
\text { social, respetando asi las diferencias y las posibilidades de comparar las } \\
\text { situaciones y las realidades de los sujetos (Organización de Estados } \\
\text { Iberoamericanos, 2004). Razón por la cual, el enfoque de las capacidades } \\
\text { permite reflexionar y valorar las opciones de elección que tiene un } \\
\text { estudiante, su docente e inclusive su director en una política de } \\
\text { flexibilización curricular en educación artística para garantizar la } \\
\text { diferencia de oportunidades. }\end{array}$ \\
\hline
\end{tabular}

Fuente: elaboración propia con base en Organización de Estados

Iberoamericanos (2004), Bolívar (2005), Formichella (2011) y Urteaga (2009)

Nota. ${ }^{\text {a }}$ Esta perspectiva de justicia social desarrolla una idea de bien y de felicidad que mide la bondad de las acciones y de las políticas en función de las consecuencias finales que ellas producen o, en otras palabras, propone la maximización de las consecuencias positivas de los actos y de las políticas como un criterio de justicia (Organización de Estados Iberoamericanos, 2004). Esto quiere decir que lo justo en esta teoría se identifica con la mayor felicidad o bienestar para la mayoría de la sociedad, incluyendo lo económicamente óptimo en términos de costo-beneficio, lo que hace imperar una racionalidad de tipo económica que termina siendo entendida como una racionalidad ética (Organización de Estados Iberoamericanos, 2004). Explican que los aportes de esta teoría de la justicia para el ámbito educativo están vinculados a resolver si todo gasto en educación es exigible en términos de justicia, o si hay sectores y tipos de prestaciones que requieran más dedicación que otros para optimizar los recursos en su distribución (Organización de Estados Iberoamericanos, 2004).

${ }^{b}$ En este sentido, si dos personas se encuentran en idéntica situación, "eso no significa que la misma sea equitativa, porque puede ser que una haya optado por dicha situación, mientras que la otra no” (Formichella, 2011, p. 8).

${ }^{\mathrm{c}}$ Entendida como el objetivo político de integrar a las personas inmigrantes, las minorías étnicas, las mujeres, los jóvenes o los discapacitados en el ámbito educativo (Urteaga, 2009).

$\mathrm{d}$ Esto se puede entender mejor con el ejemplo de dos estudiantes que poseen un título de bachiller y uno de ellos eligió no continuar sus estudios para dedicarse a los negocios, mientras que el otro se vio obligado a abandonar su proyecto de vida por alguna forma de exclusión como impuestos, ausencia de oferta y demanda en el mercado laboral, costo de vida, etc., entonces, en este caso no podría afirmarse que existe equidad educativa porque a pesar de que ambos individuos poseen el mismo título académico, no cuentan con las mismas oportunidades para hacer realidad sus opciones de vida (Formichella, 2011), por lo tanto este enfoque nos permite pensar en los alcances del principio de la política de trasformación curricular para garantizar el derecho a la educación artística en relación con las condiciones externas de la escuela, como la inserción de sus graduados en los circuitos universitarios y profesionales. 
TABLA 4.

Justificaciones para aplicar ambos enfoques teóricos en esta investigación (Cont)

\begin{tabular}{l} 
Teoria de la justicia de Rawls \\
\hline Ambos principios de la teoria de la justicia propuestos por Rawls son \\
aplicables en el ámbito educativo (Organización de Estados \\
lberoamericanos, 2004). Dichos principios en esta investigación nos \\
permiten identificar y valorar si un sistema oducativo (cada colegio, en \\
nuestro caso) es más equitativo que otro, al saber si las desigualdades \\
encontradas son ventajosas para los más desfavorecidos (Bolivar, 2005). Así \\
mismo, tener conocimiento de las diferencias o similitudes que puede haber, \\
a nivel interno y externo entre los casos de estudio, como, por ejemplo, si las \\
instituciones educativas se apoyaron en la discriminación positiva ${ }^{c}$ para lograr \\
el principio de la diferencia ampliando las posibilidades de acceso a la \\
ensefianza a las poblaciones marginadas (Bolivar, 2005).
\end{tabular}

Y porque desde esta perspectiva teórica el derecho a la educación es un bien primario que contribuye a lograr la igualdad de oportunidades, al reconocer este derecho como un derecho constitutivo de los bienes básicos que facilita las condiciones propias para el desarrollo y el ejercicio de las libertades básicas de los sujetos, así como de otros derechos (Organización de Estados Iberoamericanos, 2004).

Enfoque de las capacidades
Porque en lo relacionado con las instituciones educativas, este enfoque
teórico las considera un ámbito de especial relacionamiento entre lo
individual, lo particular y lo singular, por tal razón, la propuesta de
Amartya Sen, contribuye con la evaluación de lo que en ellas se produce,
ya que la libertad real de la que gocen las personas es la que les permitirá
desarrollar sus capacidades productivas y definir sus propios planes de
vida en el marco de una cultura compartida cuyos valores son
transmitidos, criticados y constituidos gracias a la educación
(Organización de Estados Iberoamericanos, 2004). Asi, la valoración de
la vida y los procesos educativos no tiene que ver solo con los bienes y
prestaciones que se distribuyan al interior de los itinerarios escolares,
sino también con las condiciones de posibilidad que se generen afuera de
ellos para ampliar los ámbitos de libertad de los sujetos y el ejercicio de la
misma. (Organización de Estados Iberoamericanos, 2004).
Y porque enfatiza que la educación permite el acceso a funcionamientos
diversos, permite enseńar saberes respecto a qué hacer con esos bienes, y
no solo a cómo obtenerlos, para cosntituir las capacidades como medios
valiosos para el desarrollo de un fin ulterior, que la misma institución
educativa ayuda a conformar (Organización de Estados
Iberoamericanos, 2004). En otras palabras, que las personas educadas
hayan podido integrarse con más facilidad a la sociodad en la que viven, a
nivel político, ciudadano y productivo (Formichella, 2011). Esto nos
permite complementar la justificación anterior, considerando el alcance
de las capacidades desarrolladas de los estudiantes para mejorar las
condiciones de su contexto político, económico y social.

Porque en lo relacionado con las instituciones educativas, este enfoque teórico las considera un ámbito de especial relacionamiento entre lo Amartya Sen, contribuye con la evaluación de lo que en ellas se produce, ya que la libertad real de la que gocen las personas es la que les permitirá desarrollar sus capacidades productivas y definir sus propios planes de vida en el marco de una cultura compartida cuyos valores son insmitidos, criticados y constituidos gracias a la educación la vida y los procesos educativos no tiene que ver solo con los bienes y prestaciones que se distribuyan al interior de los itinerarios escolares, so también con las condiciones de posibilidad que se generen afuera de misma. ${ }^{d}$ (Organización de Estados Iberoamericanos, 2004). no solo a cómo obtenerlos, para cosntituir las capacidades como medios valiosos para el desarrollo de un fin ulterior, que la misma institución educativa ayuda a conformar (Organización de Estados hayan podido integrarse con más facilidad a la sociedad en la que viven, nivel político, ciudadano y productivo (Formichella, 2011). Esto nos de las capacidades desarrolladas de los estudiantes para mejorar las condiciones de su contexto político, económico y social.

\footnotetext{
Fuente: elaboración propia con base en Organización de Estados Iberoamericanos (2004), Bolívar (2005), Formichella (2011) y Urteaga (2009)
}

Las justificaciones antes señaladas explican brevemente las razones por las cuales los principios de justicia de Rawls, junto con el enfoque de las Capacidades de Amartya Sen y Martha Nussbaum, son pertinentes en este estudio para analizar la forma en que se orientó la flexibilidad curricular en aras de garantizar el derecho a la educación artística en cada caso de estudio. Además, para saber si se tuvieron en cuenta criterios de distribución que les garantizaran a los estudiantes tener las mismas oportunidades para desarrollar sus capacidades. Es importante resaltar con respecto a este enfoque que, Martha Nussbaum a diferencia de Amartya Sen, lo propone como una teoría parcial de la justicia, fundamentada en la idea de vida buena para todas y cada una de las personas, con la dignidad como criterio normativo (Calvo, 2017). Esta postura va más allá de la John Rawls porque mientras su definición de justicia como equidad se refiere a los bienes primarios (libertades civiles y políticas), la de Nussbaum incluye otros aspectos fundamentales de la vida de las personas que están relacionados con su dignidad y, por lo tanto, con el ideal de justicia social, los cuales son determinados por el contexto social, económico y cultural como la religión, la afiliación política, el bienestar sexual, entre otros (Calvo, 2017). Esto es de suma importancia para esta investigación porque permite conocer cómo esos aspectos afectan y condicionan la distribución de oportunidades en la enseñanza artística en cada caso de estudio, dado que algunos de ellos son también esenciales para desarrollar las capacidades de las personas y lograr su proyecto de vida de manera digna y buena en el campo artístico.

Por todo lo anterior, la investigación entendió la equidad en educación como un principio de justicia fundamental para la formulación, implementación y evaluación de políticas educativas de flexibilización curricular, al permitir la igualdad de oportunidades en el acceso, la enseñanza, el aprendizaje, el tratamiento entre docentes y estudiantes, el desarrollo de capacidades, y en los resultados académicos de educación básica y media, esenciales para la inclusión social y el cumplimiento de los derechos humanos. 


\section{Resultados del estudio comparativo de casos}

En las tablas 5, 6 y 7 se consignan las conclusiones alcanzadas después de analizar los resultados obtenidos en cada caso de estudio. ${ }^{[18]}$

TABLA 5.

Conclusiones obtenidas por cada categoría de investigación en el caso de estudio 1

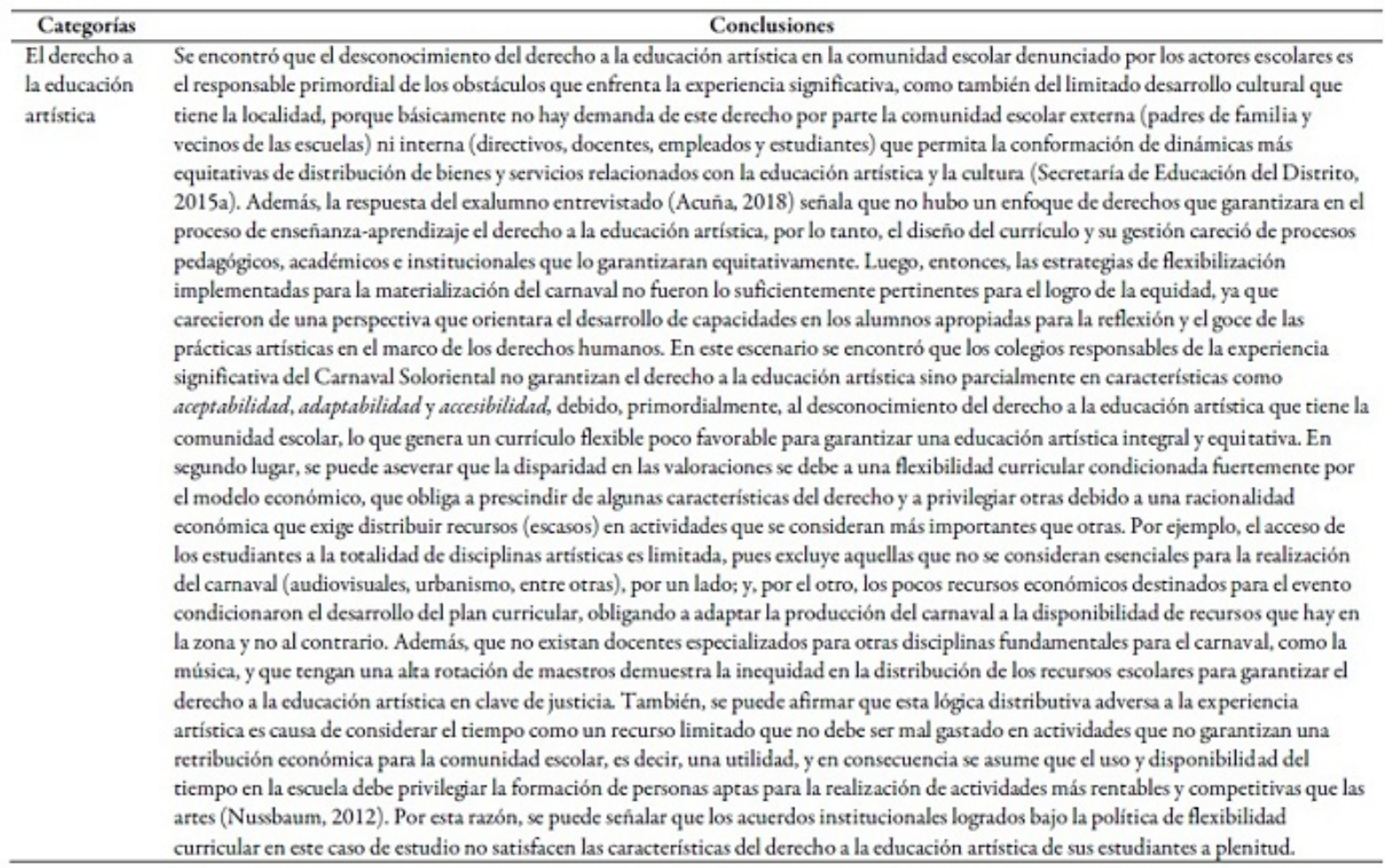

Fuente: elaboración propia

Nota. ${ }^{a}$ Enfoque pedagógico optado por los realizadores del Carnaval Soloriental, que se fundamenta en la crítica social, la autorreflexión y la consideración del conocimiento como una construcción comunitaria conformada por los intereses y las necesidades de los grupos sociales (Ministerio de Educación Nacional de Colombia, 2008b). 
TABLA 5.

\section{Conclusiones obtenidas por cada categoría de investigación...(Cont)}

\begin{tabular}{|c|c|}
\hline Categorias & Conclusiones \\
\hline $\begin{array}{l}\text { La equidad en } \\
\text { educación } \\
\text { artística en } \\
\text { básica y } \\
\text { media. }\end{array}$ & 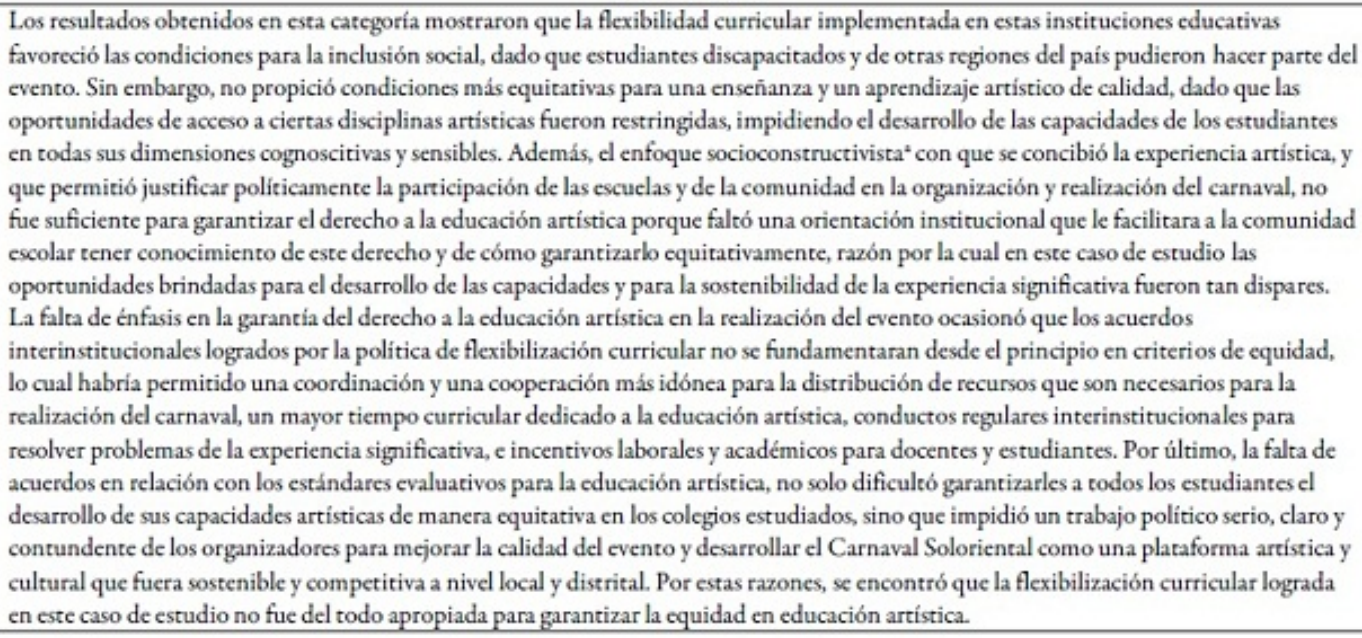 \\
\hline $\begin{array}{l}\text { La } \\
\text { flexibilidad } \\
\text { curricular de } \\
\text { la educación } \\
\text { artística. }\end{array}$ & $\begin{array}{l}\text { Se encontró que el desconocimiento del derecho a la educación por parte de la comunidad y el truncado trabajo de los onganizadores por } \\
\text { falta de apoyo político, de recursos económicos y del poco tiempo dedicado a la educación artística, dificultaron la conformación de un } \\
\text { debare en la comunidad escolar sobre flexibilidad curricular que institucionalizara de mejor manera la experiencia artística del carnaval y } \\
\text { asegurara mejores y más justas oportunidades artísticas y culturales para las comunidades de la localidad. Esto se puede afirmar en tanto } \\
\text { que la visión del carnaval no fue compartida por muchos actores escolares y la articulación de las instituciones alrededor de la educación } \\
\text { artística fue dispar. Sin embargo, el haber entendido la capacidad de adaptación de la flexibilidad curricular como un elemento } \\
\text { articulador entre las instituciones, inclusive de manera intuitiva, permitió entrelazar de una manera básica los intereses académicos e } \\
\text { institucionales de cada uno de los actores dentro y fuera de las escuelas. A pesar de todo lo anterior, se determinó que la flexibilidad en el } \\
\text { diseńo y gestión de los currículos de educación artística, a pesar de las limitaciones y falencias señaladas, permitió considerar el carnaval } \\
\text { Soloriental como una placaforma artística adecuada para la formación de comunidades críticas y productivas básicas, que pudieron } \\
\text { reflexionar sobre la reproducción de los problemas sociales y culturales que tiene la nación y el mundo, y revitalizar el debate educativo en } \\
\text { la comunidad. Es importante insistir en que la flexibilidad curricular en este caso de estudio no logra garantizar el derecho a la educación } \\
\text { artística de manera equitativa, debido a que los criterios establecidos para el logro de este principio de justicia social no logran satisfacerse } \\
\text { plenamente. De hecho, muestra que el diseńo, la gestión y evaluación del curriculo de educación artística aún carece de acuerdos } \\
\text { interinstitucionales e intrainstitucionales que les permitan a los estudiantes de la localidad gozar de las mismas oportunidades y los } \\
\text { mismos beneficios en la enseñanza y el aprendizaje artístico. }\end{array}$ \\
\hline
\end{tabular}

Fuente: elaboración propia 
TABLA 6.

\section{Conclusiones obtenidas por cada categoría de investigación en el caso de estudio 2}

\begin{tabular}{|c|c|}
\hline Categoria & Conclusiones \\
\hline $\begin{array}{l}\text { El derecho a } \\
\text { la educación } \\
\text { artística }\end{array}$ & 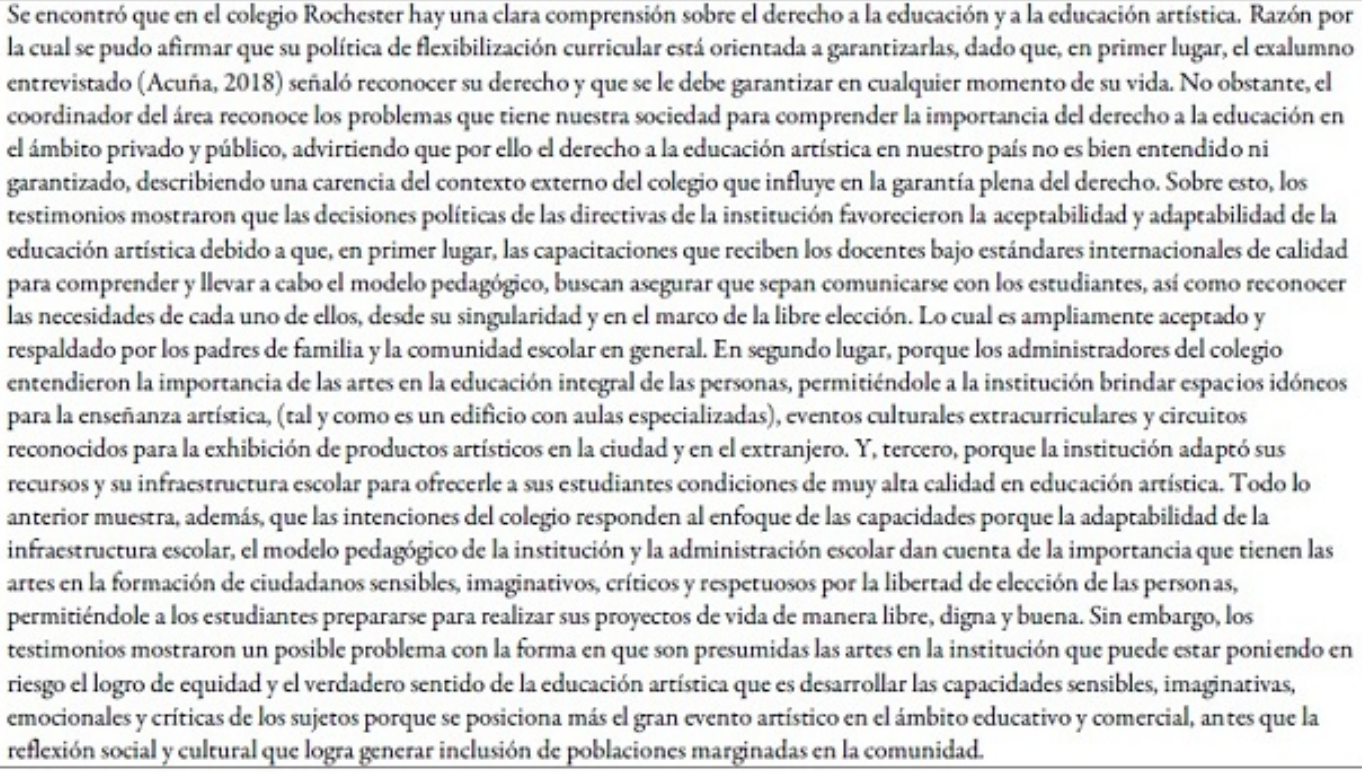 \\
\hline $\begin{array}{l}\text { La Equidad } \\
\text { en Educación } \\
\text { Artística en } \\
\text { Básica y } \\
\text { Media }\end{array}$ & 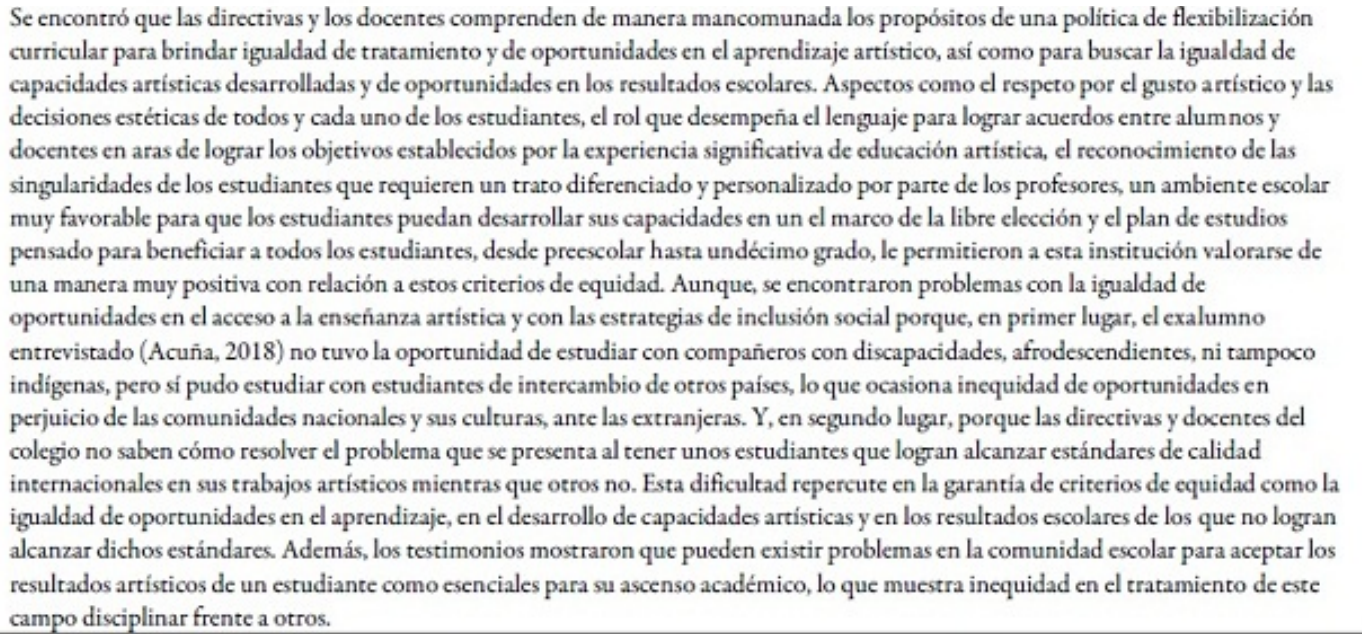 \\
\hline
\end{tabular}

Fuente: elaboración propia 
TABLA 6.

Conclusiones obtenidas por cada categoría de investigación...(Cont)

\begin{tabular}{|c|c|}
\hline Categoría & Conclusiones \\
\hline $\begin{array}{l}\text { La } \\
\text { flexibilidad } \\
\text { curricular de } \\
\text { la educación } \\
\text { artística }\end{array}$ & 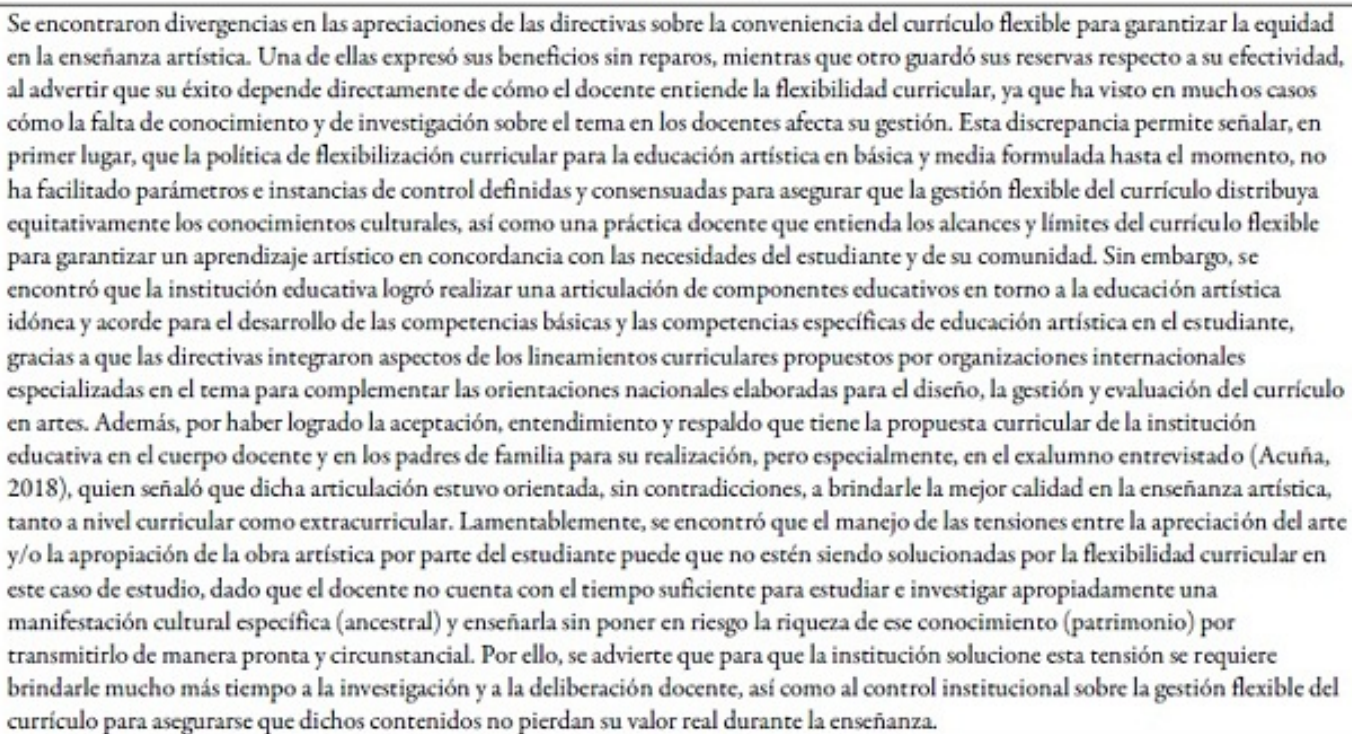 \\
\hline
\end{tabular}

Fuente: elaboración propia

TABLA 7.

Conclusiones obtenidas en cada Categoría de investigación en los casos de estudio 3

\begin{tabular}{|c|c|}
\hline Categoria & Conclusiones \\
\hline $\begin{array}{l}\text { El derecho a } \\
\text { la educación } \\
\text { artística. }\end{array}$ & 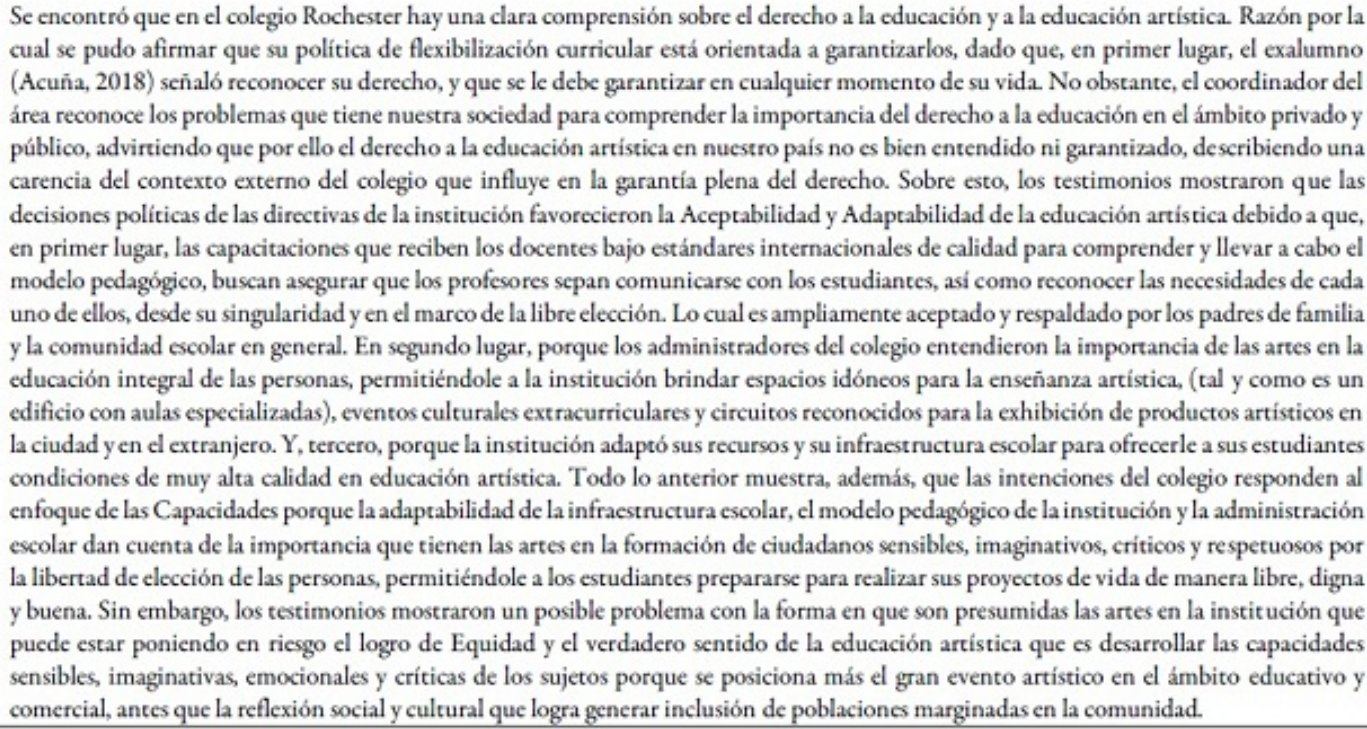 \\
\hline
\end{tabular}


TABLA 7.

Conclusiones obtenidas en cada Categoría de investigación...(Cont)

\begin{tabular}{|c|c|}
\hline ía & Conclusiones \\
\hline $\begin{array}{l}\text { La Equidad } \\
\text { en educación } \\
\text { artística en } \\
\text { Básica y } \\
\text { Media. }\end{array}$ & 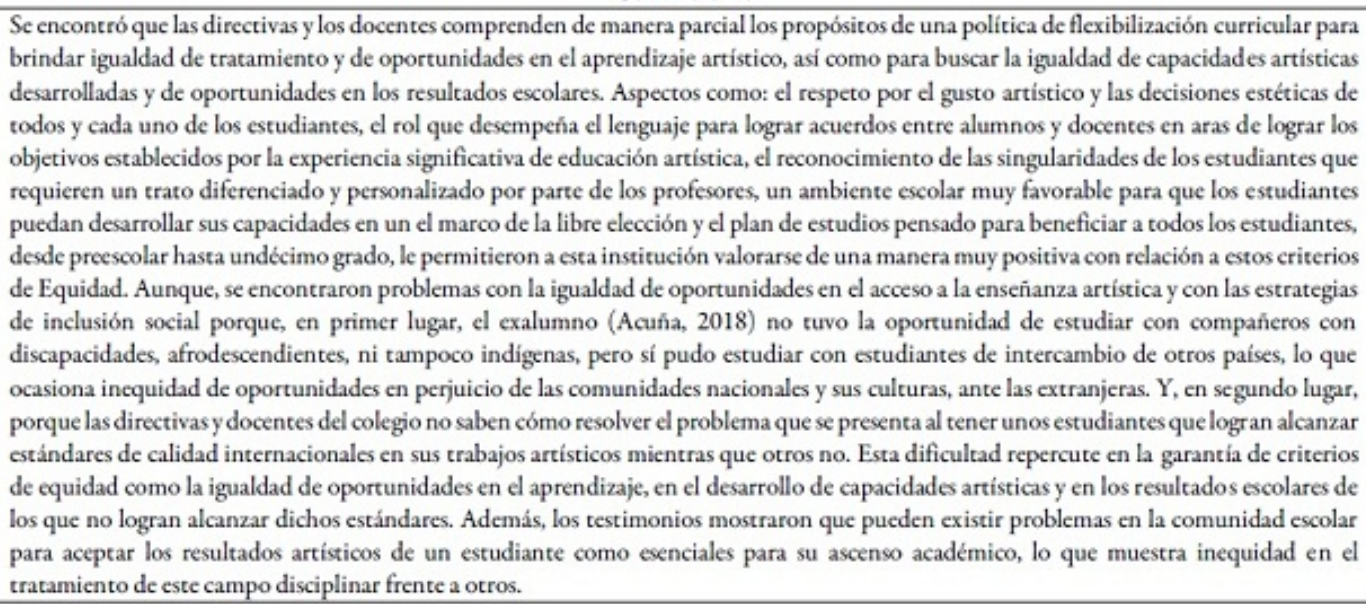 \\
\hline $\begin{array}{l}\text { La } \\
\text { flexibilidad } \\
\text { curricular de } \\
\text { la educación } \\
\text { artística. }\end{array}$ & 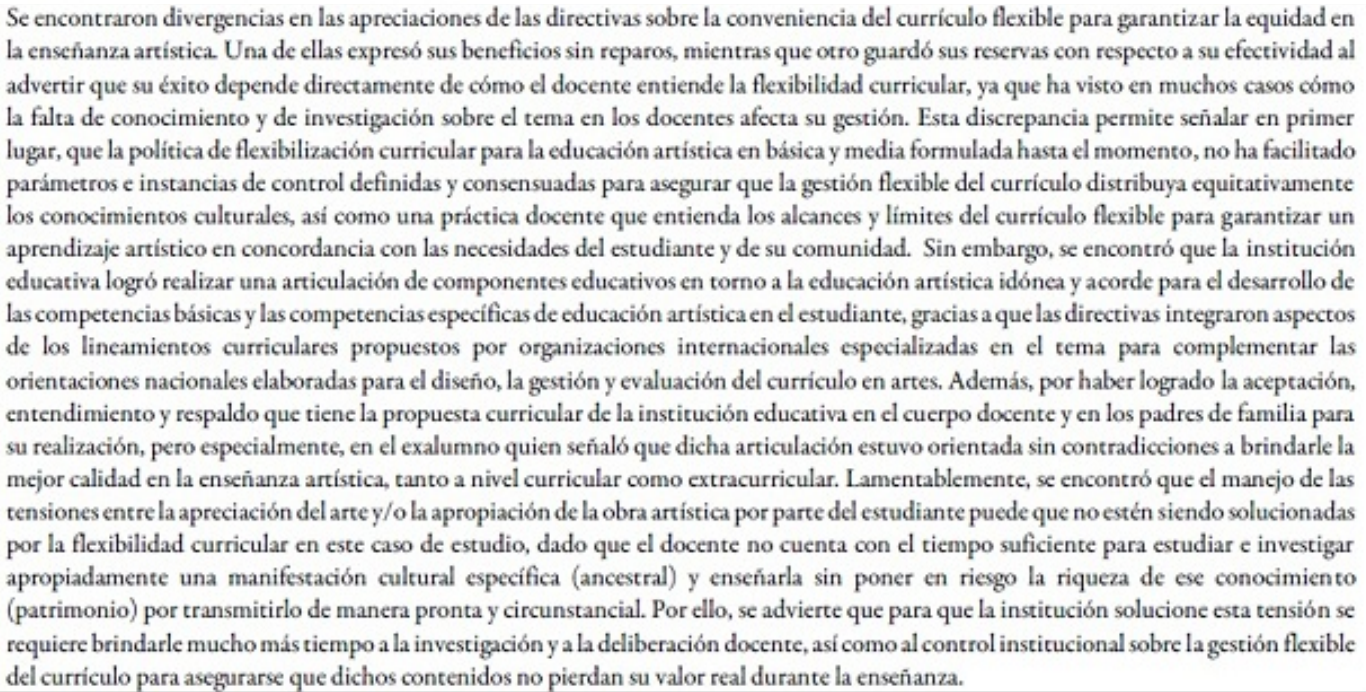 \\
\hline
\end{tabular}

Fuente: elaboración propia

En la tabla 8 se exponen los aspectos comunes y diferenciales que se encontraron entre los casos de estudio, y que condicionaron la flexibilidad curricular para garantizar equitativamente el derecho a la educación artística. 
TABLA 8.

Similitudes y diferencias entre los casos de estudio

\begin{tabular}{|c|c|}
\hline Semejanzas & Diferencias \\
\hline $\begin{array}{l}\text { Hay desconocimiento sobre el derecho a la educación artística en la } \\
\text { comunidad escolar de los casos } 1 \text { y } 2 \text {, especialmente en los padres de familia, lo } \\
\text { que impide que el currículo flexible pueda garantizar todas las características } \\
\text { de este derecho. }\end{array}$ & $\begin{array}{l}\text { Los modelos pedagógicos, las misiones y visiones de cada institución } \\
\text { educativa son diferentes, razón por la cual el diseńo, la gestión y } \\
\text { evaluación de políticas sobre flexibilización curricular varía en cada } \\
\text { uno de ellos, generando una oferta desigual de oportunidades"para el } \\
\text { desarrollo de capacidades en los estudiantes. }\end{array}$ \\
\hline $\begin{array}{l}\text { La comunidad escolar tampoco comprende la importancia del campo artístico } \\
\text { para el desarrollo económico, político, social y cultural de las localidades, lo } \\
\text { que afecta la articulación curricular y las oportunidades que debe brindar las } \\
\text { instituciones, tanto a nivel interno como externo, para el desarrollo de las } \\
\text { capacidades en los estudiantes. }\end{array}$ & $\begin{array}{l}\text { El estrato sociocconómico de los estudiantes y sus familias es } \\
\text { diferente en cada caso de estudio, lo que determina el tipo y la } \\
\text { cantidad de oportunidades brindadas por la flexibilidad curricular en } \\
\text { cada experiencia significativa para el desarrollo de capacidades } \\
\text { artísticas. }\end{array}$ \\
\hline $\begin{array}{l}\text { Hay inconformidad en la comunidad escolar de los tres casos estudiados por la } \\
\text { alta rotación de maestros (debido a contratos laborales precarios y muy } \\
\text { flexibles) que afecta la estabilidad de la flexibilidad curricular y la igualdad de } \\
\text { oportunidades brindadas para el desarrollo de capacidades en los estudiantes. }\end{array}$ & $\begin{array}{l}\text { La infraestructura fisica y administrativa es diferente en cada colegio, } \\
\text { razón por la cual la flexibilidad curricular no garantiza las mismas } \\
\text { oportunidades para el desarrollo de las capacidades de los estudiantes } \\
\text { entre los casos de estudio. Esto dificulta que las experiencias } \\
\text { significativas sean replicadas en otras instituciones sin que se afecte la } \\
\text { calidad de la obra y los criterios de equidad que fueron garantizados } \\
\text { por los casos que contaron con una mejor infraestructura escolar. }\end{array}$ \\
\hline $\begin{array}{l}\text { La falta de recursos económicos para la educación artística es un reclamo } \\
\text { reiterativo en los tres casos de estudio (aunque en los dos últimos colegios } \\
\text { cuenten con sólidas fuentes de ingresos), limitando las posibilidades de } \\
\text { articulación del curriculo flexible para brindar igualdad de oportunidades en } \\
\text { aras del desarrollo de capacidades artísticas. }\end{array}$ & $\begin{array}{l}\text { Las obras artísticas elaboradas por cada experiencia significativa } \\
\text { circulan de manera distinta en circuitos comerciales y culturales. } \\
\text { Razón por la cual, la flexibilidad curricular se articula de manera } \\
\text { distinta con el contexto escolar externo en cada caso de estudio. }{ }^{. *}\end{array}$ \\
\hline $\begin{array}{l}\text { Se exige mayor tiempo para la enseñanza artística en los tres casos de estudio, } \\
\text { debido a que los docentes quieren mejorar la calidad de la enseñanza ofrecida y } \\
\text { los estudiantes, tener acceso a todo el campo disciplinario de las artes; al } \\
\text { mismo tiempo que a conocimientos fundamentales como historia del arte y } \\
\text { teoria del arte. }\end{array}$ & $\begin{array}{l}\text { El legado cultural de cada institución educativa no es el mismo. } \\
\text { Razón por la cual la visión política, económica y social de las artes } \\
\text { varia en cada caso de estudio, condicionando la igualdad de } \\
\text { oportunidades para el desarrollo de las capacidades y la distribución } \\
\text { de conocimientos culturales, a intenciones diferentes. }\end{array}$ \\
\hline $\begin{array}{l}\text { La flexibilidad curricular en los tres casos de estudio se organizó en torno a la } \\
\text { música, el teatro, las danzas y las artes plásticas, pero no sobre otras disciplinas } \\
\text { como la fotografia, el cine, la arquitectura y el urbanismo. }\end{array}$ & $\begin{array}{l}\text { Hay instituciones educativas que cuentan con docentes y directivos } \\
\text { mejor preparados profesionalmente que otros para el diseño, la } \\
\text { gestión y evaluación de un curriculo flexible orientado a la garantia } \\
\text { del derecho a la educación artística y bajo criterios de equidad. Esto } \\
\text { ocasionó una gran diferencia y divergencia de respuestas } \\
\text { institucionales a las demandas por igualdad de oportunidades para el } \\
\text { desarrollo de capacidades del estudiante. }\end{array}$ \\
\hline
\end{tabular}

Fuente: elaboración propia

Nota. ${ }^{*}$ El segundo caso, por ejemplo, se especializa en formar docentes, mientras que los otros no, permitiéndole brindar oportunidades únicas para el desarrollo de capacidades artísticas y contar con condiciones aptas para garantizar el derecho a la educación artística. ${ }^{* *}$ Como se indicó, el primer caso tiene impacto a nivel local, el segundo a nivel distrital y nacional, y el tercero a nivel nacional y global.

Por último, se presentan a continuación, en la tabla 9, los aspectos positivos y negativos que se encontraron en la flexibilización curricular de cada caso de estudio, para garantizar el derecho a la educación artística de manera equitativa. 
TABLA 9.

Aspectos positivos y negativos de la política de flexibilidad curricular (en adelante PFC)

\begin{tabular}{|c|c|c|}
\hline Casos & Positivos & Negativos \\
\hline \multirow{3}{*}{1} & $\begin{array}{l}\text { La PFC permitió articular los planes curriculares (externamente) de } \\
\text { muchas instituciones educativas en torno a la realización y goce de la } \\
\text { experiencia significativa de educación artística. }\end{array}$ & $\begin{array}{l}\text { La PFC no logró asegurar la sostenibilidad económica, ni tampoco una } \\
\text { distribución equitativa de responsabilidades para la realización de la } \\
\text { experiencia significativa y la garantía permanente de este derecho. }\end{array}$ \\
\hline & $\begin{array}{l}\text { La PFC permitió mejorar las estrategias pedagógicas y el conjunto de } \\
\text { oportunidades que tenian los estudiantes para lograr una formación } \\
\text { ciudadana sensible y culta. }\end{array}$ & $\begin{array}{l}\text { La PFC no consideró una instancia para la evaluación y el control de la } \\
\text { gestión flexible del curriculo que garantizara la igualdad de } \\
\text { oportunidades en la enseñanza artística. }\end{array}$ \\
\hline & $\begin{array}{l}\text { La PFC mejoró la inclusión social de poblaciones históricamente } \\
\text { marginadas en la realización de la experiencia significativa para gozar } \\
\text { su derecho a la educación artistica. }\end{array}$ & $\begin{array}{l}\text { La PFC no igualó el tiempo curricular de la educación artística con el } \\
\text { que tienen otras asignaturas, ni tampoco mejoró la disponibilidad } \\
\text { completa de las disciplinas del campo artistico. }\end{array}$ \\
\hline \multirow{3}{*}{2} & $\begin{array}{l}\text { La PFC se orientó al desarrollo de capacidades en el marco de la } \\
\text { libre elección y en el respeto por las singularidades de los estudiantes. }\end{array}$ & $\begin{array}{l}\text { La PFC no facilitó la rendición de cuentas educativa en educación } \\
\text { artística a nivel externo (Pruebas Ser), poniendo en riesgo la } \\
\text { aceptabilidad del derecho a la educación artística. }\end{array}$ \\
\hline & $\begin{array}{l}\text { La PFC, en una escuela que forma maestros, facilitó espacios para } \\
\text { que los docentes y estudiantes realizaran investigaciones en } \\
\text { pedagogia y en educación artística a través del programa de } \\
\text { formación complementaria. }\end{array}$ & $\begin{array}{l}\text { La PFC no aseguró que los docentes tuvieran conocimientos } \\
\text { apropiados sobre los límites y alcances de la flexibilidad curricular para } \\
\text { garantizar el derecho a la educación artistica. }\end{array}$ \\
\hline & $\begin{array}{l}\text { La PFC logró, con recursos públicos, ofrecer condiciones y un } \\
\text { conjunto de oportunidades idóneas y sostenibles (como en el tercer } \\
\text { caso de estudio) para garantizar el derecho a la educación artística de } \\
\text { manera equitativa. }\end{array}$ & $\begin{array}{l}\text { La PFC no consideró la historia del arte y la teoría del arte como } \\
\text { disciplinas fundamentales para la formación integral de ciudadanos } \\
\text { sensibles y comprometidos con el desarrollo cultural de la nación. }\end{array}$ \\
\hline \multirow{3}{*}{3} & $\begin{array}{l}\text { La PFC permitió plantear un plan de estudios para la educación } \\
\text { artística desde preescolar hasta undécimo grado, ampliando el } \\
\text { tiempo de enseñanza y profundización artística. }\end{array}$ & $\begin{array}{l}\text { La PFC no evitó que la rotación alta de maestros afectara la garantía } \\
\text { equitativa del derecho a la educación artistica a la comunidad escolar. }\end{array}$ \\
\hline & $\begin{array}{l}\text { La PFC se formuló reconociendo el derecho a la educación artística } \\
\text { y las demás características del derecho a la educación. }\end{array}$ & $\begin{array}{l}\text { La PFC no garantizó una distribución equitativa del conocimiento } \\
\text { cultural en educación artística. }\end{array}$ \\
\hline & $\begin{array}{l}\text { La PFC mejoró el acceso a bienes y servicios esenciales para la } \\
\text { producción, distribución y circulación de productos escolares de } \\
\text { educación artística a nivel nacional e internacional. }\end{array}$ & $\begin{array}{l}\text { La PFC no aseguró que los recursos escolares garantizaran el derecho a } \\
\text { la educación artística al interior de la comunidad escolar a un costo } \\
\text { similar con respecto a los otros casos de estudio. }\end{array}$ \\
\hline
\end{tabular}

Fuente: elaboración propia

Nota. ${ }^{*}$ Véase la comparación de canastas educativas entre los casos de estudio en el Anexo.

\section{Conclusiones y aprendizajes}

Tras analizar los resultados obtenidos por esta investigación, se concluyó que los currículos flexibles han contribuido parcialmente a garantizar el derecho a la educación artística en condiciones de equidad a las comunidades escolares de los casos de estudio, pero este derecho debe ser garantizado a plenitud por el Estado colombiano al ser fundamental para el cumplimiento de los demás derechos ${ }^{[19]}$ (Rodríguez y Ojeda, 2015). Por tal razón se puede afirmar que la política educativa sobre flexibilidad curricular no ha sido del todo adecuada para garantizarlo plenamente, como se observa en la tabla 10. 
TABLA 10

Impedimentos de la PFC para garantizar equitativamente el derecho a la educación artística

\begin{tabular}{|c|c|}
\hline & Impedimentos \\
\hline 1 & $\begin{array}{l}\text { Hay casos donde su formulación, implementación y evaluación no se ha orientado a garantizar el derecho a la educación artistica en todas sus } \\
\text { características y dimensiones, debido al desconocimiento que tienen las comunidades escolares sobre este derecho y a cómo debe ser garantizado, } \\
\text { limitando la enseñanza artistica al desarrollo de manualidades y formas de entretenimiento. }\end{array}$ \\
\hline 2 & $\begin{array}{l}\text { De igual manera, el desconocimiento del derecho a la educación artística en la comunidad escolar ocasiona que el diseño, la gestión y la rendición de } \\
\text { cuentas de una política educativa sobre flexibilización curricular, no se fundamente ni se mida por el logro de criterios en equidad que brinden igualdad } \\
\text { de oportunidades en el acceso, el aprendizaje, el tratamiento, el desarrollo de capacidades y en los resultados escolares de educación artística, } \\
\text { dificultando la garantia plena y justa de este derecho. }\end{array}$ \\
\hline 3 & $\begin{array}{l}\text { Dado que las articulaciones curriculares están condicionadas por el tipo de infraestructura arquitectónica, administrativa, académica, pedagógica y } \\
\text { profesional que tiene cada institución educativa, la implementación de estrategias para garantizar el derecho a la educación artistica y brindar una } \\
\text { oferta equitativa de oportunidades a cada miembro de la comunidad escolar (tanto a nivel interno como externo) es limitada porque cada } \\
\text { infraestructura escolar es diferente. }\end{array}$ \\
\hline 4 & $\begin{array}{l}\text { El valor que tiene la educación artística difiere entre comunidades escolares, determinando los alcances internos y externos de la política de } \\
\text { flexibilización curricular, dado que en algunos casos se reconoce su importancia para el desarrollo económico, político, social y cultural de las } \\
\text { localidades, mientras que en otros no. Esto afecta la Equidad en educación artística porque hay colegios que brindan un mejor conjunto de } \\
\text { oportunidades para el desarrollo de las capacidades individuales y colectivas que otros. }\end{array}$ \\
\hline 5 & $\begin{array}{l}\text { El currículo flexible no asegura un tiempo propicio para que se pueda garantizar la igualdad de oportunidades en el desarrollo de capacidades artísticas, } \\
\text { una enseńanza integrada con otros campos del conocimiento, ni tampoco una distribución más justa y equicativa de los conocimientos culturales } \\
\text { porque la distribución del tiempo asignado para la educación artística con respecto al que tienen otras áreas académicas sigue siendo inferior. }\end{array}$ \\
\hline 6 & $\begin{array}{l}\text { La flexibilidad curricular no necesariamente asegura el acceso equitarivo a mejores recursos económicos, humanos o materiales para garantizar igualdad } \\
\text { de oportunidades en el desarrollo de capacidades, asi como tampoco la sostenibilidad financiera de las experiencias significativas de educación artística, } \\
\text { dado que cada institución educativa tiene ingresos desiguales, compite de manera distinta y en condiciones diferentes en los mercados educativos y } \\
\text { culturales. }\end{array}$ \\
\hline
\end{tabular}

Fuente: elaboración propia

Por otro lado, considerando que las investigaciones sobre rendición de cuentas en el sector educativo señalan que las respuestas de carácter local a las evaluaciones curriculares tienen una mayor significación a nivel general que la sospechada en un principio (McCormick y James, 1997), y que los resultados de los estudios del Ministerio de Cultura indicaron como causa del deplorable estado de la educación artística en el país que la sociedad colombiana no valora ni reconoce esta asignatura como área fundamental del conocimiento (Ministerio de Cultura de Colombia, 2005), la presente investigación puede afirmar que las políticas de flexibilidad curricular implementadas durante los últimos 10 años no han sido del todo eficaces, toda vez que no han revertido la tendencia señalada en dichos informes. Esta afirmación se respalda en que la flexibilidad curricular implementada en los tres casos estudio no pudo garantizar a plenitud el derecho a la educación artística, tampoco lograr a cabalidad los criterios de equidad para educación artística en básica y media propuestos en esta investigación, y mucho menos resolver la desigualdad de oportunidades que existe entre los casos de estudio.

No obstante, es importante resaltar que los problemas detectados en esta investigación, que impidieron a las instituciones educativas estudiadas garantizar de manera equitativa el derecho a la educación artística en básica y media a través de la flexibilidad curricular, son causados por un modelo educativo que está centrado en desarrollar capacidades para la productividad económica, y en el que no se percibe la importancia sustantiva de las artes para la formación y el cultivo de la persona (Nussbaum, 2010). De ahí que se hayan encontrado muchos reclamos por la falta de recursos escolares para la educación artística reiteradamente en los casos de estudio.

Así que para contrarrestar esta visión economicista que se ha cernido sobre la educación, es prioritario comprender y hacer entender que "el conocimiento fáctico y la lógica no alcanzan para que los ciudadanos se relacionen bien con el mundo que los rodea" (Nussbaum, 2010, p. 131), sino que se necesitan de las Artes y las Humanidades para poder complementar nuestro conocimiento sobre la realidad y desarrollar las capacidades de los sentidos, la imaginación y el pensamiento, junto con las emociones (Nussbaum, 2010, 2012, 2014). Estas capacidades nos permiten pensar cómo sería estar en una situación diferente a la que nos encontramos en el presente, o inclusive suponer cómo sería nuestra vida si tuviéramos la oportunidad de vivir las experiencias de otra persona (Nussbaum, 2010); así como ayudarnos a realizar análisis profundos 
de sus relatos, entendiendo los sentimientos, motivaciones y esperanzas que la llevaron a actuar de una manera determinada (Nussbaum, 2010). Pero, sobre todo, nos permiten desarrollar sensiblemente elementos claves para la formación ciudadana y el fortalecimiento de la democracia, como lo son la comprensión y la empatía, porque cultivan el respeto, preservan la cohesión comunitaria y contribuyen a la integración social (Nussbaum, 2010, 2012, 2014). Por ello, consideramos prioritario que una política de flexibilización curricular desarrolle estas capacidades al ser esenciales no solo para la convivencia y el logro de una vida buena, sino también para reducir conscientemente la brutal desigualdad de oportunidades que encontramos persistente, entre la educación artística de un colegio privado y uno público en nuestra investigación.

En la tabla 11 se exponen las estrategias que a nuestro parecer solucionarían los problemas señalados a través de una política de flexibilización curricular para educación artística en básica y media con equidad.

TABLA 11.

Estrategias para mejorar la garantía del derecho a la educación artística

\begin{tabular}{l}
\hline Recomendaciones \\
\hline 1) Adoptar el enfoque de las capacidades para que la comunidad escolar pueda formular, implementar y evaluar estrategias curriculares orientadas al \\
desarrollo humano en todas sus dimensiones y a la garantía plena del derecho a la educación y de los demás derechos que de este se desprenden, como lo \\
es el de la educación artística. \\
\hline 2) Orientar el diseño, la gestión y la evaluación de las articulaciones curriculares al logro de criterios en equidad para garantizarle a la comunidad escolar \\
oportunidades más justas en el acceso, el aprendizaje, el tratamiento, el desarrollo de capacidades y en los resultados escolares de educación artística. Así \\
como, para mejorar la inclusión e integración social de las poblaciones marginadas. \\
\hline 3) Solucionar mediante la flexibilización curricular las falencias en infraestructura escolar que tenga la institución educativa para garantizar el derecho \\
a la educación artística plenamente. Los acuerdos interinstitucionales entre organizaciones civiles, estatales, industrias culturales y otras comunidades \\
escolares contribuyen a solucionar y complementar dichas necesidades, al mismo tiempo que incrementan la importancia de la educación artística en \\
las localidades disminuyendo la tremenda diferencia de oportunidades que existe entre colegios públicos y privados del país. \\
4) Abrirle espacio a una veeduría institucional (rendición de cuentas) que haga seguimiento y control sobre el diseño, la gestión y evaluación de las \\
políticas sobre flexibilidad curricular implementadas, tanto a nivel interno como externo de las instituciones, para constatar que las articulaciones \\
curriculares realizadas por los maestros no afecten la igualdad de oportunidades logradas para el desarrollo de las capacidades y estén complementando \\
las que hagan falta en su práctica docente.
\end{tabular}

Fuente: elaboración propia

Nota. Estas recomendaciones fueron pensadas para que cualquier institución educativa elabore una política de flexibilización curricular en básica y media, orientada a resolver los problemas instrumentales y de justicia social que se hallaron en esta investigación, y que impidieron garantizar el derecho a la educación artística de manera equitativa. Lo anterior, en el marco de un enfoque de justicia, que como ya se explicó, está basado en los derechos humanos y proporciona una lógica para una comparación correcta de los logros alcanzados

en materia de desarrollo, y en cuestiones que afectan la igualdad de oportunidades (Nussbaum, 2012).

${ }^{a}$ Entendida como toda empresa u organización que produce, reproduce, conserva y difunde bienes y servicios artísticos y culturales bajo criterios industriales y comerciales, es decir, en serie y aplicando estrategias de carácter económico basadas en la explotación del trabajo asalariado y en la forma en que la mercancía es consumida en el mercado (Ministerio de Cultura de Colombia, 2010a).

${ }^{\mathrm{b}}$ Durante los últimos 10 años, no se lograron acuerdos interinstitucionales entre los tres casos de estudio de esta investigación para contribuir al mejoramiento o a la sostenibilidad de las experiencias artísticas. Para más detalle sobre esto véase en el anexo 7.9 del documento maestro (Acuña, 2018).

${ }^{\mathrm{c}}$ Parámetros mensurables, razonables y creíbles sobre la hechura del producto artístico como: la perdurabilidad de las materias usadas para su elaboración, el valor de uso y valor simbólico de la obra (Narváez, 2008).

d Aunque la ley no menciona la flexibilidad curricular, sí reconoce la educación artística y cultural como un sector que conjuga junto con otros, la Economía Creativa. Se sugiere involucrarlos en la PFC para mejorar la equidad en la enseñanza artística.

${ }^{\mathrm{e}}$ Entendido como un módulo curricular o extracurricular destinado a enseñar cómo los procesos de producción determinan la creación de valor en una obra artística, cómo son asignados, cómo se transforman y en qué proporción esos valores de uso son influidos por el producto en el mercado para generar plusvalía (Narváez, 2008). Así mismo para entender cómo este proceso afecta los imperativos democráticos que garantizan los derechos a la libre expresión, a la cultura (Kellner, 1998) y a la educación artística. 
TABLA 11.

Estrategias para mejorar la garantía del derecho a la educación artística (Cont)

\begin{tabular}{l} 
Recomendaciones \\
\hline 5) Asegurar que la flexibilidad curricular brinde una mejor distribución del tiempo escolar a la educación artística, así como que se impartan contenidos \\
esenciales para el desarrollo estético de los estudiantes como teoria e historia del arte y las disciplinas completas del campo artístico, las cuales brindan \\
posibilidades de articulación con otros campos del conocimiento y animan a los estudiantes a encontrarse con interpretaciones y concepciones de \\
filósofos, historiadores y críticos del arte (Efland, Freedman y Stuhr, 2003) esenciales en su formación ciudadana. \\
\hline 6) Formular políticas de flexibilización curricular bajo estándares de calidad medibles' para que durante su implementación y evaluación se garantice \\
plenamente el derecho a la educación artística y la equidad de oportunidades, Esto incluye criterios y métodos de evaluación acordes y actualizados con \\
las demandas de producción, exhibición, distribución, circulación y consumo de bienes y servicios culturales (Narváez, 2008) para que la obra artística \\
elaborada por la comunidad escolar cuente con mejores oportunidades para insertarse en el mercado y pueda contribuir al desarrollo de una industria \\
cultural en su localidad que promueva la riqueza y proteja su legado cultural (Ministerio de Cultura de Colombia, 2010a). Y para esto, se recomienda \\
estructurar los acuerdos entre instituciones educativas y organizaciones artísticas civileso industrias culturales, apoyándose en la Ley 1834o Ley Naranja ${ }^{d}$ \\
que facilita el logro de estos propósitos. \\
\hline 7 ) La política de flexibilización curricular debe contar con un componente pedagógico para que la comunidad escolar pueda entender el contexto \\
competitivo en el que están inmersas las producciones artísticas y puedan adaptar sus estrategias lo mejor posible a las necesidades económicas que \\
alteran las concepciones del valor que tienen los bienes y servicios de esta índole (Narváez, 2008), y afectan la garantía plena de los derechos culturales, \\
entre ellos el de la educación artística (Ministerio de Cultura de Colombia, 2010a).
\end{tabular}

Fuente: elaboración propia

Para terminar, se requiere urgentemente que las comunidades escolares, artistas, representantes gremiales y líderes políticos dupliquen sus esfuerzos para divulgar, fomentar y exigir que las instituciones educativas, sociales, económicas y culturales garanticen el derecho a la educación artística equitativamente en nuestro país. Es importante resaltar que no se puede confiar en la flexibilidad curricular para garantizar este derecho a plenitud si no se realizan acciones intersectoriales que les permitan a las poblaciones más marginadas contar con las mismas oportunidades que tienen los más privilegiados de acceder, por ejemplo, a una galería de arte, a un museo nacional o planear su proyecto de vida buena y digna en el sector artístico. Y para esto, es imperativo que la formulación, implementación y evaluación de políticas sobre flexibilidad curricular no se realice bajo la discrecionalidad de las instituciones educativas, intención de estas políticas en las últimas décadas, sino que por el contrario, las autoridades públicas y organizaciones civiles avaladas por las comunidades, el Estado y sus gobiernos, le aseguren a la ciudadanía local y regional que dichas decisiones están siendo ejecutadas para disminuir la tremenda brecha de inequidad en educación artística que se encontró persistente en esta investigación, y que muy seguramente se profundiza en las regiones más alejadas del centro del país. No hay que olvidar que la educación rural se encuentra muy rezagada con respecto a la urbana. Según la Encuesta Nacional de Calidad de Vida, de cada 100 matriculados en la zona rural, 71 llegaron a $6^{\circ}$ grado, 60 a $9^{\circ}$ y 48 a $11^{\circ}$ en 2008 (Ministerio de Educación Nacional de Colombia, 2011), situación que permite afirmar que a estas generaciones de estudiantes no se les garantizó equitativamente su derecho a la educación y mucho menos su derecho a la educación artística, en tanto que más de la mitad de ellos no logró culminar el bachillerato, y, por ende, el ciclo de educación artística de estos niveles educativos que es tan esencial para la formación ciudadana y cultural de las personas en la reconstrucción social, el desarrollo de los pueblos y la protección identitaria de la nación (Ministerio de Cultura de Colombia, 2010a). 
TABLA 12.

Componentes canasta educativa colegio público histórico y proyectado 2017 y 2018

\begin{tabular}{lrrrrr}
\hline Inflación $^{*}$ & & & $7,5 \%$ & $4,09 \%$ & $3,5 \%$ \\
\hline Año & 2014 & 2015 & 2016 & 2017 & 2018 \\
\hline Recursos humanos & 1.670 .760 & 1.731 .910 & 1.861 .803 & 1.937 .951 & 2.005 .779 \\
\hline Planta & 218.116 & 226.099 & 243.056 & 252.997 & 261.852 \\
\hline Alumno & 102.363 & 106.110 & 114.068 & 118.734 & 122.889 \\
\hline Administración & 52.168 & 54.077 & 58.133 & 60.510 & 62.628 \\
\hline Alimentación y transporte & 490.577 & 508.532 & 546.672 & 569.031 & 588.947 \\
\hline Costo Canasta Educativa Distrital $^{* *}$ & 2.533 .984 & 2.626 .728 & 2.823 .733 & 2.939 .223 & 3.042 .096 \\
\hline
\end{tabular}

Fuente: elaboración propia con datos provenientes de la canasta educativa real, promedio oficial 2014 y 2015 de la Secretaría de Educación del Distrito (2015c)

Nota. No se tomaron los datos calculados para colegios con jornada completa $(40 \times 40)$ debido a que no todos los colegios públicos estudiados ofrecen este tipo de currículo. Sin embargo, de manera complementaria, se realizó el cálculo y se obtuvo que la jornada completa es $56 \%$ más costosa que la no completa.

*El dato de la inflación de 2017 se tomó del Dane (2018), y el dato de inflación proyectada se tomó del Banco de la República (2017).

** Los valores son en pesos colombianos.

TABLA 13.

Cálculo del costo de Canasta educativa en el Colegio Rochester

\begin{tabular}{lrrrrr}
\hline Año & 2014 & 2015 & 2016 & 2017 & 2018 \\
\hline Pago alumno básica y media ${ }^{*}$ & n.d & n.d & n.d & 1.500 .000 & 1.552 .500 \\
\hline Primaria & n.d & n.d & n.d & 2.470 .304 & 2.559 .900 \\
\hline Promedio Simple & n.d & n.d & n.d & 1.985 .152 & 2.056 .200 \\
\hline $\begin{array}{l}\text { Costos Canasta Educativa } \\
\text { Rochester }\end{array}$ & n.d & n.d & n.d & 1.985 .152 & $2.056 .200^{* *}$ \\
\hline
\end{tabular}

Fuente: elaboración propia con base en las tarifas educativas del Colegio Rochester (2017)

Nota. ${ }^{*}$ Este valor fue indicado por un exalumno entrevistado (Acuña, 2018).

${ }^{* *}$ Con el costo proyectado de un estudiante para 2018 en este colegio se podría pagar el

costo de 17 alumnos en un colegio público. Todos los valores son en pesos colombianos. 
TABLA 14.

Comparación de costos por componentes educativos entre el colegio Rochester y la educación pública distrital para 2018

\begin{tabular}{|c|c|c|c|c|}
\hline \multicolumn{5}{|l|}{ Componente alimentación y transporte } \\
\hline & Rochester & & Público & \\
\hline Alimentación & & 376.000 & & \\
\hline Transporte & & 540.000 & & \\
\hline \multirow[t]{2}{*}{ Total componente alimentación y transporte } & & 916.000 & & 588.438 \\
\hline & Rochester & & Público & \\
\hline \multirow[t]{2}{*}{ Componente recurso humano y administración } & & $26.000 .000^{*}$ & & 2.066 .619 \\
\hline & Rochester & & Público & \\
\hline \multirow[t]{2}{*}{ Componente Planta y recursos físicos ${ }^{* *}$} & & 1.031 .000 & & 261.626 \\
\hline & Rochester & & Públicos & \\
\hline Costo final canasta educativa 2018 & & 30.003 .200 & & 3.039 .466 \\
\hline
\end{tabular}

Fuente: elaboración propia con base en las tarifas educativas del Colegio Rochester (2017), junto con datos de la canasta educativa real promedio del distrito 2014-2015 de la Oficina Asesora de Planeación Grupo Programas y proyectos de la Alcaldía mayor de Bogotá (Secretaría de Educación del Distrito, 2015c) Nota. ${ }^{*}$ Se asumió que el valor del bono prepago cubre los gastos de recursos humanos y administración en dicha institución, incluidos los salarios devengados por docentes y empleados. ** Se tomaron los costos de rubros como la matrícula, Biblio banco, afiliación Asopadres, anuarios digitales, impresos y seguros de accidentes, cuya información se encuentra publicada en la página web de la Institución en lo referente a tarifas, dado que no se tuvo acceso a la información financiera de la institución. No obstante, puede que una porción del bono prepago pague el mantenimiento de la planta física del colegio. De todas maneras, el costo final de esta canasta educativa es producto de todos los rubros que aparecen publicados en la página electrónica de la institución, junto con datos obtenidos en las entrevistas realizadas durante la investigación.

\section{Comentarios}

1. Con el valor de la matrícula del colegio privado se puede pagar el costo de 17 alumnos en un colegio público.

2. El pago por alimentación y transporte del colegio privado es casi 2 veces el costo del mismo componente en un colegio público.

3. Con el gasto en recursos humanos del colegio privado se paga 12 veces el costo del mismo componente en un colegio público.

4. Con el costo de planta y recursos físicos del colegio privado se paga 4 veces el mismo componente en uno público.

5. La canasta educativa del colegio privado es 10 veces la de un colegio público del distrito.

\section{Referencias}

Acuña. J. (2018). El currículo flexible en la educación artística bogotana: ¿una muestra de equidad o inequidad? Análisis comparativo de las experiencias significativas de educación artística que fueron reconocidas por el Ministerio de Educación Nacional en 2008 y de sus trayectorias hasta el 2018 (tesis de maestría). Pontificia Universidad Javeriana, Bogotá, Colombia. Recuperado de https://www.repository.javeriana.edu.co/handle/10554/34891

Alfiz, I. (1997). El proyecto educativo institucional propuestas para un diseño colectivo. Buenos Aires: Aique.

Ariza, S. (2017, 25 de septiembre). El Sentido del Arte en la Escuela. Magisterio. Recuperado de https://www.magis terio.com.co/articulo/el-sentido-del-arte-en-la-escuela

Banco de la República. (2017). Proyecciones macroeconómicas de analistas locales y extranjeros. Bogotá: Banco de la República. Recuperado de: https://www.banrep.gov.co/es/encuesta-proyecciones-macroeconomicas 
Bolívar, A. (2005). Equidad educativa y Teorias de la justicia. Revista Iberoamericana sobre Calidad, Eficacia y Cambio en Educación, 3(2), 42-69. Recuperado de https://www.redalyc.org/pdf/551/55103205.pdf

Bracho, T., y Hernández, J. (2009, 25 de septiembre). Equidad Educativa: Avances en la definición de su concepto. En R. López (Presidencia), Interrelaciones Educación-Sociedad. Simposio llevado a cabo en el X Congreso Nacional de Investigación Educativa, Veracruz, México. Recuperado de https://www.comie.org.mx/congreso/memoriael ectronica/v10/pdf/area_tematica_10/ponencias/1852-F.pdf

Caballero, F. (2006). La teoría de la Justicia de John Rawls. Iberóforum. Revista de ciencias sociales de la universidad Iberoamericana, 1(2), 1-22. Recuperado de https://www.redalyc.org/pdf/2110/211015573007.pdf

Cabaluz-Ducasse, J. (2016). Pedagógias críticas latinoamericanas y filosofía de la liberación: potencialidades de un diálogo teórico-político. Educación y Eduadores, 19(1), 67-88. https://www.doi.org/10.5294/edu.2016.19.1.4

Calvo, Á. (2017, junio). Enfoque de las Capacidades y emociones políticas. La construcción de una Sociedad democrática en el pensamiento de Martha Nussbaum.Seminario llevado a cabo en la Pontificia Universidad Javeriana, Bogotá, Colombia.

Castillo, M., Cuan, J., Hernández, L., Manrique, A. Robayo, A., y Santamaría, M. (2015). Flexibilidad curricular en las instituciones del Distrito Capital (Tesis de Maestría). Pontificia Universidad Javeriana, Bogotá, Colombia.

Centro de Investigación y Educación Popular. (2006). El Derecho a la Educación, Documentos DHESC. Bogotá: Antropos.

Colegio Rochester. (2017). Colegio Rochester, proyecto educativo. Recuperado de https://www.rochester.edu.co/p royecto-educativo/

Comisión Colombiana de Juristas. (2004). El disfrute del derecho a la educación en Colombia. Informe alterno presentado a la Relatora Especial de las Naciones Unidas sobre el derecho a la educación. Bogotá: Autor. Recuperado de https://www.coljuristas.org/documentos/libros_e_informes/el_disfrute_del_derecho_a_la_ed ucacion.pdf

Comisión Económica Para América Latina y el Caribe. (2006). El Derecho a la Educación Una Tarea Pendiente en América Latina y el Caribe. Nueva York: Naciones Unidas. Recuperado de https://www.unicef.org/lac/Desafi os_Nro3_Educacion_Ago2006(2).pdf

Congreso de la República de Colombia. (1994, 8 de febrero). Ley 115. Por la cual se expide la ley general de educación. Bogotá: Autor. Recuperado de https://www.mineducacion.gov.co/1621/articles-85906_archivo_pdf.pdf

Dane. (2018). Comunicado de prensa. Índice de Precios al Consumidor (IPC). Diciembre 2017. Recuperado de http s://www.dane.gov.co/files/investigaciones/boletines/ipc/cp_ipc_dic17.pdf

De Zubiría, J. (2015). El nuevo índice para evaluar la calidad de la educación. Semana, 64.

Del Corral, P. (2005). Una Nueva Mirada a la Educación Artística desde el Paradigma del Desarrollo Humano (Tesis doctoral). Universidad Complutense, Madrid, España. Recuperado de https://www.biblioteca.ucm.es/tesis/bb a/ucm-t28786.pdf

Díaz, M. (2002). Flexibilidad y educación Superior en Colombia. Bogotá: Secretaria General-Procesos Editoriales. Recuperado de https://www.acreditacion.unillanos.edu.co/CapDocentes/contenidos/dis_ambientes_metodo s_pedagogicos/Memoria3/flexibilidad_educacion_colombia.PDF

Efland, A., Freedman, K., y Stuhr, P. (2003). La Educación en el arte posmoderno. Madrid, España: Paidós.

Escalona, L. (2008). Flexibilidad curricular: elemento clave para mejorar la educación bibliotecologica. Investigación bibliotecológica, 22(44), 143-160. Recuperado de https://www.scielo.org.mx/scielo.php?script=sci_arttext\&p id $=$ S0187-358X2008000100008

Formichella, M. (2011). Análisis del concepto de equidad educativa a la luz del enfoque de las capacidades de Amartya Sen. Revista educación, 35(1), 1-36. Recuperado de https://www.redalyc.org/articulo.oa?id=44018789001

Gimeno, J. (2010). La función abierta de la obra y su contenido. Revista Electrónica Sinéctica, 34, 11-43. Recuperado de https://www.redalyc.org/articulo.oa?id=99815691009

Grupo Interdisciplinario de Investigación en Currículo. (2008a). Currículo y flexibilidad curricular. Series vicerrectoría de Docencia, entrega 1, 8-37. Recuperado de 
de https://www.comunicaciones.udea.edu.co/autoevaluacioncomunicaciones/images/Sitio_informe/Anexos/ Otros\%20documentos/Folleto\%201\%20Flexibilidad\%20curricular.pdf

Grupo Interdisciplinario de Investigación en Currículo. (2008b). Referentes jurídicos de la flexibilidad curricular en la educación superior en Colombia. Recuperado de https://www.huitoto.udea.edu.co/curriculo/Menu/DocumentosCurriculo/ARTICULOS\%20SOBRE\%2 0CURRICULO\%20Y\%20FLEXIBILIDAD\%20CURRICULAR/LA\%20FLEXIBILIDAD\%20CURRICU LAR\%20Y\%20REFERENTES\%20JURIDICOS\%20EN\%20LA\%20EDUCACINO\%20SUPERIOR\%20C OLOMBIANA.doc

Grupo Interdisciplinario de Investigación en Currículo. (2008c). La flexibilidad curricular y el contexto socioeconómico. Series Vicerrectoria de Docencia, entrega 2, 11-31. Recuperado de https://www.yumpu.com/ es/document/view/28017620/entrega-2-la-flexibilidad-curricular-y-el-contexto-socioeconamico

Huertas, M. (2010). Reflexiones sobre educación artística y el debate disciplinar en Colombia. Revista educación y pedagogía, 22(58), 165-176. Recuperado de https://www.aprendeenlinea.udea.edu.co/revistas/index.php/revi staeyp/article/view/9743/0

Kellner, D. (1998). Vencer la línea divisoria: estudios culturales y economía política. En M. Ferguson (ed.), Economía Política y Estudios Culturales (pp. 186-212). Madrid: Bosch.

Kemmis, S. (1986). El Curriculum: Más allá de la teoría de la reproducción (Pablo Manzano, trad.). Madrid: Morata.

McCormick, R., y James, M. (1997). Evaluación del currículo en los centros escolares. México: Morata.

Ministerio de Cultura de Colombia. (2005). Educación Artística en Colombia, Estado del Arte. En J. Ardila (ed.), Educación artística y cultural, un propósito común. Documentos para la formulación de una política pública colombiana. Cuadernos de educación artística 1 (pp. .93-131). Bogotá: JHimpregraft Ltda.

Ministerio de Cultura de Colombia. (2007a). Educación artística y cultural, un propósito común. Documentos para la formulación de una política pública colombiana. Cuadernos de educación artística 1. Bogotá: JHimpregaft Ltda.

Ministerio de Cultura de Colombia. (2007b). Plan Nacional de Educación Artística 2007-2010. Documento de Trabajo. Bogotá: Autor. Recuperado de https://www.mesadeartes.files.wordpress.com/2009/09/plan-nacional -de-educacion-artistica.doc

Ministerio de Cultura de Colombia. (2010a). Compendio de Políticas Culturales. Bogotá: Autor.

Ministerio de Cultura de Colombia. (2010b). Construcción de una política pública para la educación artística en Colombia Balance 2002-2010. Bogotá: Autor. Recuperado de https://www.unesco.org/culture/en/artseducat ion/pdf/fp103ruizromero.pdf

Ministerio de Educación Nacional de Colombia. (2000). Educación Artística Lineamientos curriculares Áreas obligatorias y fundamentales. Bogotá: Nomos.

Ministerio de Educación Nacional de Colombia. (2005). Definición de Flexibilización Curricular. Glosario de términos. Bogotá: Autor. Recuperado de https://www.mineducacion.gov.co/1621/article-82793.html

Ministerio de Educación Nacional de Colombia. (2008a). Primeras conclusiones del Foro de Educación Artística y Cultural. Colombia Aprende. La red del conocimiento. Bogotá: Autor. Recuperado de https://www.colombia aprende.edu.co/html/home/1592/article-173457.html

Ministerio de Educación Nacional de Colombia. (2008b). Arte, Cultura y Patrimonio. Orientaciones Pedagógicas para la educación artística y cultural. Educación Preescolar Básica y Media (Borrador). Bogotá: Autor. Recuperado de https://www.mineducacion.gov.co/cvn/1665/articles-172594_archivo_pdf.pdf

Ministerio de Educación Nacional de Colombia. (2010). Orientaciones pedagógicas para educación artística en básica y media. Bogotá: Autor. Recuperado de https://www.mineducacion.gov.co/1759/articles-241907_archivo_pd f_orientaciones_artes.pdf

Ministerio de Educación Nacional de Colombia. (2011). Manual para la formulación y ejecución de planes de Educación rural. Calidad y Equidad para la población de la zona rural. Bogotá: Autor. Recuperado de https://w ww.mineducacion.gov.co/1759/articles-329722_archivo_pdf_Manual.pdf

Ministerio de Educación Nacional de Colombia. (2017a). Comunicación Externa General Vía Mail-2017-EE-041110. Bogotá: Autor. 
Ministerio de Educación Nacional de Colombia. (2017b). Colombia ya tiene su Plan Nacional Decenal de Educación. Bogotá: Autor. Recuperado de https://www.mineducacion.gov.co/1759/w3-article-363197.html

Narváez, A. (2008). El Concepto de Industria Cultural, Una Aproximación desde la economía Política. En Industrias culturales, músicas e identidades: una mirada a las interdependencias entre medios de comunicación, sociedad y cultura (pp. 29-58). Bogotá: Pontificia Universidad Javeriana.

Nussbaum, M. (2010). Sin fines de lucro: por qué la democracia necesita de las humanidades. Buenos Aires: Katz Editores.

Nussbaum, M. (2012). Crear capacidades propuesta para el desarrollo humano. Madrid: Paidós

Nussbaum, M. (2014). Emociones políticas ępor qué el amor es importante para la justicia? Bogotá: Planeta.

Organización de Estados Iberoamericanos. (2004). Proyecto Equidad y Políticas Educativas. En Estudio sobre ética pública en el ámbito educativo - justicia social y educación. Madrid: Autor. Recuperado de https://www.camp us-oei.org/calidad/equipol5.htm

Ortega, F. (2003). La Equidad en educación Básica. Revista Latinoamericana de Estudios Educativos, 2(2), 119-134.

Rawls, J. (2011). Liberalismo Político (M. Báez, y S. René, trads.). Bogotá: Fondo de Cultura Económica.

Rodríguez, O., y Ojeda, P. (2015). Educación: ¿derecho o servicio? Casos Colombia y Cuba. Praxis, 11, 132-149. Recuperado de https://www.dialnet.unirioja.es/descarga/articulo/5907255.pdf

Secretaría de Educación del Distrito. (2010). Resolución 05186 por la cual se revoca parcialmente la resolución 5581 del 11 de agosto de 1997 y se procede al cierre del establecimiento educativo denominado colegio rural los Soches centro educativo Distrital. Bogotá: Autor.

Secretaría de Educación del Distrito. (2015a). Caracterización del Sector Educativo Localidad de Usme. Recuperado de http://www.educacionbogota.edu.co/archivos/SECTOR_EDUCATIVO/ESTADISTICAS_EDUCATI VAS/2015/5-Perfil_localidad_de_Usme.pdf

Secretaría de Educación del Distrito. (2015b). Caracterización del Sector Educativo Localidad Antonio Nariño. Recuperado de https://www.educacionbogota.edu.co/archivos/SECTOR_EDUCATIVO/ESTADISTICAS _EDUCATIVAS/2015/15-Perfil_localidad_de_Antonio_Nario.pdf

Secretaría de Educación del Distrito. (2015c). Costo canasta educativa 2014-2015. Oficina asesora de planeación. Bogotá: Grupo Programas y proyectos.

Tomasevski, K. (2004). El asalto a la educación. Barcelona: Intermón Oxfam.

Unesco. (2006). Hoja de Ruta para la educación artística. Conferencia Mundial sobre Educación Artística: Construir capacidades creativas para el siglo XXI. Lisboa: Autor. Recuperado de https://www.unesco.org/fileadmin/mul timedia/HQ/CLT/CLT/pdf/Arts_Edu_RoadMap_es.pdf

Urteaga, E. (2009, octubre-diciembre). Políticas de discriminación Positiva. Revista de Estudios Políticos (Nueva Época), 146, 181-213. Recuperado de https://www.cepc.gob.es/publicaciones/revistas/revistaselectronicas?ID $\mathrm{R}=3 \& \mathrm{IDN}=680 \& \mathrm{IDA}=27541$

Zapata, S. (2012). Teorías del currículo y concepciones curriculares. En Diseño Curricular Problematizador: Una opción para la elaboración del currículo en Derechos Humanos desde la pedagogía crítica. Recuperado de https ://www.docs.google.com/document/d/113PAozssGj_57tVs45mFl-UfpDpsuU2oHAX6HSaxOb4/edit

\section{Anexo. Comparación de Canastas Educativas entre el colegio privado y los públicos estudiados}

\section{Procedimiento y supuestos}

1. Se tomaron datos registrados en la canasta educativa 2014-2015 de la Secretaría de Educación del Distrito (2015c) para colegios públicos oficiales (no en concesión) y se proyectaron a un término de 3 años con la inflación publicada por el Banco de la República (2017). 
2. Se tomó como referencia comparativa el Colegio Rochester porque es la única institución educativa privada estudiada, y porque los valores a los que se tuvo acceso fueron del año escolar 2017-2018.

3. Para hacer comparables los datos, se tomaron los valores por componentes del informe de la Secretaría de Educación del Distrito (2015c) y se proyectaron de acuerdo con los cálculos de inflación para el 2018 del Banco de la República (2017). Asimismo, se tomó el dato de la matrícula para básica y media mencionado por el exalumno (2016-2017) del Rochester, junto con valores de primaria, y se proyectaron para determinar lo que costará en 2018 (Acuña, 2018).

4. Se realizaron promedios simples de los costos de primaria y secundaria para obtener el total de la canasta educativa promedio.

5. A partir de los valores obtenidos para 2018 se calcularon las diferencias entre canastas educativas.

\section{Notas}

[1] Por ejemplo, la proporción de docentes de educación artística en educación preescolar, básica y media en el 2007 no superó el $6 \%$ y este porcentaje fue inferior al de otras áreas de humanidades como lengua castellana e idiomas extranjeros (20\%), matemáticas (15\%), ciencias naturales y educación ambiental (13,7\%), ciencias sociales, historia, geografía, constitución política y democracia $(12,6 \%)$, educación física $(7,1 \%)$, tecnología e informática (7\%); y con respecto al total de los programas de educación superior relacionados con las artes, representó solo un (2\%) (Ministerio de Cultura de Colombia, 2007). Otro estudio indicó, por ejemplo, que en el país se contó en el 2010 con 230.000 plantas docentes, de las cuales solo 5000 correspondieron a docentes de artes y de educación artística, lo que equivale a tan solo el $(2,17$ \%) de la comunidad total de maestros. También, señaló que, de los 855 artistas y docentes vinculados durante ese mismo año al programa para la profesionalización de docentes en artes, Colombia Creativa, 545 estudiantes correspondieron al área de música $15,04 \%, 115$ a danza (3,17\%), 160 a teatro (4,41\%) y solo 35 (0,9\%) a educación artística (Ministerio de Cultura de Colombia, 2010b).

[2] Un año después, la Secretaria de Educación del Distrito, apoyada por la gestión de los ministerios de Educación y de Cultura, la Organización de Estados Iberoamericanos (OEI), la International Society for Education through Art (INSEA) y la corporación cultural colombiana (AMBAR), dirigida por Olga Lucia Olaya Parra, reconoció 48 experiencias más de educación artística, pero en el marco del Festival Artístico Escolar del Distrito (Secretaría de Educación del Distrito, 2010).

[3] El 22 de noviembre de 2010, los supervisores de la localidad quinta del distrito inspeccionaron las instalaciones del colegio para constatar información recibida en la Dirección de Educación de Usme sobre el peligroso estado del colegio, y encontraron, en una visita, que esta institución tenía un alto grado de vulnerabilidad en su planta física, muy riesgoso para el cuerpo docente y estudiantil ante un evento sísmico, obligándolos a trasladar 62 estudiantes y 3 profesores al colegio aledaño Las Violetas, y clausurar la institución por no encontrarse en condiciones adecuadas para su funcionamiento, debido a que el colegio había sido construido en un predio sin legalización y sin licencias de construcción (Secretaría de Educación del Distrito, 2010).

[4] Movimiento pedagógico latinoamericano multifacético por tener afluentes teórico-políticos de tipo democrático popular, socialista, marxista, libertario y cristiano que confluyeron en el pensamiento pedagógico contra-hegemónico de: Paulo Freire, Moacir Gadotti, Darcy Ribeiro, Gaudencio Frigotto, Demerval Saviani, Tomaz T. da Silva (Brasil), Carlos Cullen, Carlos A. Torres, Roberto Follari, Adriana Puiggrós, Claudia Korol, Norma Michi (Argentina), Rolando Pinto, Hugo Zemelman (Chile), Iván Illich, Carlos Nuñez, Roberto Abarca (México), Marco R. Mejía (Colombia), José Rebellato (Uruguay), Roseli Caldart, Bruno Baronett, Norma Michi y la Universidad Intercultural Amawtay Wasi (Cabaluz-Ducasse, 2016).

[5] En el portal virtual del Ministerio de Educación Nacional no aparece la fecha en que fue publicada esta definición. Se le solicitó a la cartera pública, mediante un Derecho de Petición a Consulta, aclarar este dato. Respondieron que fue publicada en el 2005.

[6] La ley 30 de educación superior, la constitución nacional, ponencias de congresistas, entre otros (Grupo Interdisciplinario de Investigación en Currículo, 2008b).

[7] El pedagogo critico Henry Giroux (1943) define al currículum oculto como "aquellas normas no dichas, valores y creencias implicadas en la transmisión a los estudiantes por medio de las reglas implícitas que estructuran la rutina y las relaciones sociales en la escuela y en la vida del aula" (Zapata, 2012, p. 21).

[8] Elliot Eisner (1933-2014) profesor de arte, definió el currículum nulo como "todo aquello que la escuela no enseña y que puede ser tanto o más importante que aquello que enseña. En consecuencia, el currículum nulo se refiere esencialmente a dos aspectos: (a) todos aquellos procesos intelectuales que la escuela deja de lado, y (b) materias, contenidos o asignaturas que están ausentes en el currículum explícito” (Zapata, 2012, p. 18).

[9] Elliot Eisner definió el currículum explícito como "todo aquello que la escuela ofrece mediante ciertos propósitos y planes manifiestos y públicos. Se trata entonces de la oferta educativa cuidadosamente preparada y que se concretiza en un 
conjunto de objetivos educacionales, planes de estudio, programas, textos escolares, guías didácticas, etc." (Zapata, 2012, p. 16).

[10] Instancia pensada para el seguimiento y control de las adaptaciones y diversificaciones realizadas por la comunidad escolar a los elementos y componentes del currículo (Alfiz, 1997), entendiéndola también como una rendición de cuentas indispensable para comprobar si la gestión curricular está cumpliendo con las expectativas de la comunidad escolar (McCormick y James, 1997).

[11] La declaración Universal de los Derechos humanos, el Pacto Internacional de los Derechos Económicos, Sociales y Culturales, el Pacto internacional de los Derechos Civiles y Políticos, el Protocolo de San Salvador, la Convención sobre los Derechos del Niño, el Convenio 182 sobre la peores formas de trabajo Infantil de la OIT, la Convención sobre la Eliminación de Todas las Formas de Discriminación Contra la Mujer, la Convención Interamericana sobre la Eliminación de Todas las Formas de Discriminación Contra las Personas con Discapacidad, entre muchos más (Centro de Investigación y Educación Popular, 2006).

[12] Lineamientos curriculares para la educación Artística (2000) y las Orientaciones Pedagógicas para educación Artística en Básica y media (2010), ambos elaborados por el Ministerio de Educación Nacional de Colombia.

[13] Como la constitución política o las decisiones económicas y sociales que definen cargos y posiciones, cargas y beneficios, poderes e inmunidades, para todas las personas que se rigen por ellas (Caballero, 2006).

[14] Los derechos, libertades, oportunidades, ingresos, riqueza, y el auto respeto (Centro de Investigación y Educación Popular, 2006).

[15] Para comprender en detalle estos dos poderes morales ver Rawls (2011, pp. 66-71).

[16] Totalidad de oportunidades disponibles para elegir y actuar en una situación política, social y económica (Centro de Investigación y Educación Popular, 2006).

[17] Rasgos y aptitudes entrenadas y desarrolladas en interacción con el entorno social, económico, familiar y político (Centro de Investigación y Educación Popular, 2006).

[18] Para apreciar detalladamente la codificación de los datos obtenidos en cada caso de estudio, así como las valoraciones positivas y/o negativas que obtuvieron las categorías y subcategorías de investigación, junto con sus análisis preliminares, véase las matrices analítico-descriptivas a nivel micro, meso y macro que se elaboraron en el informe final de este trabajo académico que reposa en la biblioteca de la Universidad Javeriana (Acuña, 2018).

[19] Derechos culturales, económicos, políticos y civiles. Es fundamental que la educación garantice estos derechos porque así se logra el bienestar general de todos, idea que comparten el enfoque del desarrollo humano y de las capacidades (Del Corral, 2005).

* Artículo de investigación

\section{Licencia Creative Commons CC BY 4.0}

Cómo citar este artículo: Acuña Castillo, J. A. (2019). El currículo flexible en la educación artística bogotana: ¿una experiencia de equidad o inequidad? Papel Politico, 24(1). https://doi.org/10.11144/ Javeriana.papo2 4-1.cfea 